\title{
Assessing plant water status in a hedgerow olive orchard from thermography at plant level
}

García-Tejero*, I.F., Hernández¹, A., Padilla-Díaz², C.M., Díaz-Espejo², A., Fernández², J.E.

${ }^{1}$ Centro IFAPA "Las Torres-Tomejil". Ctra. Sevilla-Cazalla Km. 12.2 41,200. Alcalá del Río (Sevilla) 2Irrigation and Crop Ecophysiology Group, Instituto de Recursos Naturales y Agrobiología de Sevilla (IRNAS, CSIC), Avenida de Reina Mercedes, n. ${ }^{\circ}$ 10, 41012 Seville, Spain.

The authors belong to the Unidad Asociada "Gestión sostenible de los recursos suelo y agua". e-mail corresponding authors: ivanf.garcia@juntadeandalucia.es

\section{Abstract}

Water scarcity is the most limiting factor in many irrigated areas of Mediterranean countries such as South Spain. Olive growing has been traditionally associated to rain-fed agriculture, although irrigation and practices related to intensive agriculture have been progressively introduced, requiring a more precise irrigation scheduling to save water. Thermal imaging is among the alternatives to assess the crop water status, especially when deficit irrigation (DI) strategies are applied. However, this technique requires of new advances to be more user friendly and robust for practical usage. The aims of this study were: i) to define threshold values of canopy temperature $\left(T_{C}\right)$, Crop Water Stress Index (CWSI) and the temperature difference between canopy and the surrounding air ( $\Delta T_{\text {canopy-air }}$ for the assessment of the olive water status when a DI strategy is applied; ii) to define the best time of the day and the best area of the canopy to carry out thermal measurements, and iii) to obtain relationships between thermal indicators and main physiological parameters useful to estimate the crop water status from thermal data. The trial was conducted during 2015, in a hedgerow olive orchard (SW Spain) with 8-year-old trees (Olea europaea L., cv. Arbequina), under three irrigation regimes: a full-irrigation treatment (FI) and two regulated deficit irrigation treatments aimed to supplying $45 \%$ of the irrigation needs. In one of them, irrigation was scheduled from leaf turgor pressure related measurements (45RDITP). In the other, the crop coefficient approach was used to schedule irrigation (45RDI $\mathrm{lc}_{\mathrm{c}}$ ). Significant correlations between $T c$ versus stem water potential $\left(\Psi_{\mathrm{st}}\right)$ and leaf gas-exchange parameters (stomatal conductance to water vapor, $g_{s} ;$ net $\mathrm{CO}_{2}$ assimilation, $A_{N}$; transpiration, $E$ ) were obtained ( $p \leq 0.05$ ), in particular from measurements taken at 10:30 GMT in the lower part of the sunlit side of the canopy. Moreover, the relationships between both $\Delta T_{\text {canopy-air }}$ and CWSI with the monitored physiological variables were very robust. We concluded that values of $\Delta T_{\text {canopy-ar }}$ higher than $0{ }^{\circ} \mathrm{C}$ and values of $C W S I$ up to 0.2 reliably reflect the plant water stress. Our results, therefore, suggest that both $\Delta T_{\text {canopy-air }}$ and $C W S /$ measured at midday provide reliable information on the tree water status and are useful to schedule irrigation in hedgerow olive orchards, especially under DI conditions. 
41 Keywords: Thermography, thermal indexes, water stress, irrigation scheduling, leaf-gas exchange 42 parameters, water potential.

\section{1.- Introduction}

46 Olive represents the most important tree crop in the worldwide in terms of surface, with a global area close to $11 \times 10^{6}$ ha. Most of the growing areas are located in Mediterranean European countries, being

48 Spain the most relevant in terms of production, with over $2.5 \times 10^{6}$ ha devoted to this crop, from which ca. 400.000 ha are under irrigation (MAGRAMA 2016).

50 The number of olive orchards has significantly increased in the last few years and, in many countries,

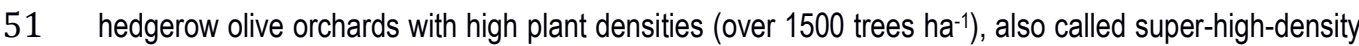

52 (SHD) orchards, are becoming popular. This type of orchard covers a surface of ca. 100,000 ha (Rius 53 and Lacarte, 2015). According to forecast predictions (IPCC, 2014), water can be the most limiting 54 factor for olive growing, particularly for irrigated SHD orchards (Vossen et al., 2004). Therefore, 55 effective water management is crucial to increase the productivity of this natural resource, especially in 56 areas such as South Spain, where climatic conditions are characterized by rainfall scarcity and a highly 57 irregular spatial and temporal distribution of the rainfall events (Garcia-Tejero et al., 2013).

58 Deficit irrigation (DI) strategies are highly effective for both improving water productivity and achieving a 59 sustainable agricultural development. A properly chosen DI strategy saves water without highly affecting 60 yield, and it has usually with a positive impact on quality (Fereres and Soriano, 2007; Geerts and Raes, 61 2009; Ruiz-Sánchez et al., 2010). Moreover, DI limits excessive growth, which is important in SHD 62 orchards, where tree size has to be controlled for both optimum illumination and mechanical harvesting 63 (Cuevas et al., 2013). In this line, authors such as Fernández et al. (2013), Gómez del Campo (2013) 64 and Padilla-Díaz et al. (2016) have demonstrated that regulated deficit irrigation (RDI) can be a suitable 65 strategy to improve irrigation water management and water productivity in SHD olive orchards. RDI 66 strategies are based on avoiding excessive water stress in the periods of the growing cycle when the 67 crop is highly sensitive to drought, so the effective monitoring of plant water status along the crop 68 growing cycle becomes crucial (Poblete-Echeverría et al., 2014; Fernández 2014a).

69 There is a substantial amount of literature on the usefulness of different methods for the continuous 70 monitoring of crop water status, such as those based on the use of dendrometers (Moriana et al., 2010 71 or Cuevas et al., 2010), sap-flow (Fernández et al., 2008a; Fernández, 2014a) or leaf turgor pressure 72 probes (Zimmerman et al., 2008; Fernández et al., 2011â). Studies on their applicability to commercial 73 orchards proved that additional information on crop-water status is often required to properly evaluate 74 the information collected by those sensors (Fernández, 2014b). Thus, leaf or stem water potential and 75 gas-exchange related measurements, apart of being used alone to monitor the plant water status, are 76 often combined with the methods mentioned above. These water stress indicators have also their 77 limitations. According to Martín-Vertedor (2011) and Fernández (2014a,b), leaf or stem water potential 
measurements are good indicators of olive water status, but they are not suitable for precision 79 agriculture because they cannot be automated. In fact, their use is based on destructive, non80 continuous, high labour- and time-consuming measurements. Something similar occurs with gas81 exchange measurements, such that they are more widely used with research purposes than in 82 commercial orchards (Poblete Echeverría et al., 2016).

83 New irrigation approaches, such as precise irrigation, are technically demanding. This is behind the 84 increasing interest in the use of remote sensing to monitor crop water status at different scales (at plant 85 or orchard level). In this sense, thermal imaging emerged as a non-invasive approach to assess the 86 crop-water status and to schedule irrigation, as probed from findings in citrus trees (García-Tejero et al., 87 2011; González-Dugo et al., 2014); almonds (Garcia-Tejero et al., 2012), vines (Costa et al., 2012; 88 García-Tejero et al., 2016) and olives (Berni et al., 2009; Poblete-Echeverría et al., 2014, 2016), among 89 other crops. The principle of thermography relies on the leaf energy balance. Water stress induces 90 stomatal closure, which in turn limits leaf transpiration, and hence the evaporative cooling process. This 91 results in higher leaf/canopy temperature values (Jones, 1999, 2004). Thermal readings provide reliable 92 information on the crop physiological status. Still, relationships between thermal information and main 93 physiological parameters such as the stomatal conductance to water vapour $\left(g_{\mathrm{s}}\right)$, net $\mathrm{CO}_{2}$ assimilation $94\left(A_{N}\right)$, transpiration $(E)$, or the crop water status (in the basis on the leaf or stem water potential) are 95 usually required to properly evaluate the information provided by thermal readings (Jones 2004; Jones 96 et al., 2009). These relationships, however, depend on weather variables as $T_{\text {air, }}$ incident radiation, the 97 angle of incident radiation, wind speed and vapour pressure deficit (Jones, 1999; 2004). They also 98 depend on monitoring proceedings (González-Dugo et al., 2012; Costa el al., 2013), cultivars (Costa et 99 al., 2012; García-Tejero et al., 2016) and developmental stage (Cohen et al., 2015), among other 100 factors. This has led to the testing of different strategies to optimize thermography, which included the 101 development of effective protocols for field measurements based on thermal indices (Jones et al., 2002; 102 2009; Grant et al., 2006; Möller et al., 2007; Baluja et al., 2012; Bellvert et al., 2014) and robust 103 relationships between thermal information and physiological parameters. However, some questions are 104 still under debate, e.g. which is the most practical, although robust, thermal index that can be a proxy of 105 plant physiological traits (e.g. leaf gas-exchange behavior). Another matter of debate is whether the 106 thermal measurements could be directly used, without any additional relationship with other 107 physiological variables, and whether threshold values, similar to those defined for stem or leaf water 108 potential, or stomatal conductance, can be established.

109 We hypothesize that thermography could be a suitable approach to assess the crop water status in a 110 SHD olive orchard. To test our hypothesis, we carried this work in a representative, fully productive SHD 111 olive orchard with the aims of: (i) to derive threshold values for the plant water status from thermal 112 related data collected in the orchard (canopy temperature, $T_{c}$; the temperature difference between 113 canopy and the surrounding air, $\Delta T_{\text {canopy-air; }}$ and the crop water stress index, CWSI) ; and (ii) to derive 114 relationships between thermal readings and main physiological variables (stem water potential, $\psi_{\mathrm{st}}$; 
stomatal conductance to water vapor, $g_{s}$; net $\mathrm{CO}_{2}$ assimilation, $A_{N}$, and transpiration, $E$ ). We explored

116 the suitability of taking the thermal readings at different moments of the day and in different locations of

117 the canopies.

118

119 2.- Material and Methods

120 2.1.- Experimental Site

121 The trial was conducted during the irrigation season of 2015, in a super-high-density olive (Olea

122 europaea L., cv. Arbequina) orchard located at $25 \mathrm{~km}$ of Seville $\left(37^{\circ} 15^{\prime} \mathrm{N}, 5^{\circ} 48^{\prime} \mathrm{W}\right)$. The trees were

123 planted in 2007 at the top of $0.4 \mathrm{~m}$ high ridges and spaced $4 \mathrm{~m} \times 1.5 \mathrm{~m}$ (1667 trees ha-1), with the rows

124 oriented N-NE to S-SW.

125 The orchard soil is an Arenic Albaqualf (USDA, 2010) with a sandy loam top layer (77.7\% sand, $20.1 \%$

126 clay and $2.2 \%$ silt) of $1.73 \mathrm{Mg} \mathrm{m}^{-3}$ bulk density ( $\rho$ ) and soil hydraulic conductivity near saturation ( $\left.\mathrm{K}_{\text {sat }}\right)$

127 of $40.7 \mathrm{~cm}_{\text {day }}{ }^{-1}$. Downwards there was a sandy clay layer ( $60.9 \%$ sand, $37.1 \%$ clay and $2.0 \%$ silt)

128 with $\rho=1.82 \mathrm{Mg} \mathrm{m}^{-3}$ and $\mathrm{K}_{\mathrm{sat}}=3.54 \mathrm{~cm}_{\text {day }}{ }^{-1}$. The average depth from the top of the ridges to the clayey

129 soil layer was $0.6 \mathrm{~m}$. The clay layer was not reached by the roots, since the maximum depth of the root

130 system was $0.45 \mathrm{~m}$ (Diaz-Espejo et al., 2012).

131 Trees were irrigated with an automatic controller (Agronic 2000, Sistemes Electrònics PROGRÉS, S.A.,

132 Lérida, Spain) and a pipe line per row, with three $2 \mathrm{~L} \mathrm{~h}^{-1}$ drippers per tree, spaced $0.5 \mathrm{~m}$. Fertilizers

133 were injected into the irrigation system once a week during the irrigation period, receiving all trees the

134 same amount of nutrients, enough to cover the crop needs (Fernández et al., 2013).

135 The climate of the experimental area is Mediterranean, with mild winters and hot dry summers. Most

136 rainfall events in the area occurs between September and May, the summers being dry and hot. The

137 average values of precipitation and potential evapotranspiration are $537.3 \mathrm{~mm}$ and $1504.0 \mathrm{~mm}$,

138 respectively (2010-2015 period). During the hottest months (July and August) the maximum values of

139 air temperature can easily go over $40^{\circ} \mathrm{C}$, whereas in the coolest months (December and January) air

140 temperature rarely drops below $-5^{\circ} \mathrm{C}$.

\section{2.2.- Experimental design and irrigation treatments}

143 The experimental design was a randomized complete block with four replicates per treatment. The

144 experimental unit $\left(192 \mathrm{~m}^{2}\right)$ had four rows with eight trees per row, being the eight central trees (four 145 trees for the two central rows) considered as sampling trees, surrounded by 24 border trees. Three

146 irrigation treatments were defined: (i) A full irrigation (FI) treatment, in which the trees were daily 147 irrigated to replace $100 \%$ of the irrigation needs (IN). The latter were calculated as the difference 148 between crop evapotranspiration $\left(E T_{C}\right)$ and effective precipitation $\left(\mathrm{P}_{\mathrm{e}}\right)$. $E \mathrm{~T}_{\mathrm{C}}$ was calculated with the crop 149 coefficient approach (Allen et al., 1998; see Fernández et al., 2013, for details). (ii) A regulated deficit 150 irrigation treatment (45RDIcc) aimed to replace 45\% of IN (see Padilla-Díaz et al., 2016, for details). 151 Basically, daily irrigation amounts (IA) similar to IN were applied in the three periods of the growing 
cycle when the crop is most sensitive to water stress, defined as Period 1 (around bloom, in April)

153 Period 2 (during the maximum rate of pit hardening, in June) and Period 3 (during the stage of fast oil

154 accumulation, from the end of August to mid-September) (Fernández, 2014a). Between Periods 1 and 2

155 an irrigation event per week was applied when the soil water content was below $70 \%$ of the maximum

156 soil water holding capacity. Between Periods 2 and 3 , two irrigation events per week were applied (iii) a

157 second 45RDI treatment similar to the already described, but in which irrigation was scheduled from leaf

158 turgor pressure readings (45RDItr) (see Padilla-Díaz et al., 2016, for details).

\section{2.3.- $\underline{\text { Soil and Plantplant measurements }}$}

161 The effect of the irrigation treatments on main physiological variables, including canopy temperature,

162 was established from measurements in June 18th (day of year -DOY- 169), July $2^{\text {nd }}, 16^{\text {th }}$ and $22^{\text {th }}$ (DOY

163 183, 197 and 203), August $6^{\text {th }}, 13^{\text {th }}$ and 27 $7^{\text {th }}$ (DOY 218, 225 and 239), and September 10th (DOY 253).

164 Measurements of stem water potential at midday $\left(\psi_{\mathrm{st}}\right)$ were made with a Scholander-type pressure

165 chamber (PMS Instrument Company, Albany, Oregon, USA). One leaf per tree close to a main branch

166 was sampled, from two representative trees per plot $(n=8)$, at around 12:00 GTM, the time for

167 minimum $\psi_{\text {st }}$ in olive. The chosen leaves were wrapped in aluminum foil ca. $2 \mathrm{~h}$ before sampling.

168 Measurements of stomatal conductance to water vapor $\left(g_{\mathrm{s}}\right)$, net $\mathrm{CO}_{2}$ assimilation $\left(A_{N}\right)$ and transpiration

169 (E) were made with a portable infrared gas analyzer (LI-6400; LiCor Inc., Lincoln, Nebraska, USA), with

170 a $6 \mathrm{~cm}^{2}$ transparent leaf chamber and the air-flow rate set at $350 \mu \mathrm{mol} \mathrm{s}^{-1}$. Measurements were taken in

171 one fully expanded and sunlit leaf per tested tree, using 8 trees per irrigation treatment $(n=8)$.

172 Measurements were made around 08:30 GMT, the time for maximum $g_{\mathrm{s}}$ in olive.

173 Canopy temperature $(T c)$ was derived from thermal images were made on the same days that the 174 mentioned physiological measurements, both at 08:30 and 12:00 GTM, and both at the bottom (1.5 m

175 from the soil surface) and the top (2.5 $\mathrm{m}$ from the soil surface) of the sunlit side of eight trees per

176 treatment $(n=8)$. These regions were previously defined, and the canopy surface taken in each image

177 corresponded with a single tree (the first one for the down area of the canopy, and the second one for

178 the upper area of the canopy). We use a ThermaCam (Flir SC660, Flir Systems, USA, 7-13 $\mu \mathrm{m}$,

$179640 \times 480$ pixels). Each pixel corresponded to an effective temperature reading and the emissivity $(\varepsilon)$ was

180 set at 0.96 . The background temperature was determined by measuring the temperature of a crumpled

181 sheet of aluminum foil placed near the sampled leaves using $\varepsilon=1$ (Jones et al., 2002). The imager was

182 placed perpendicularly to the canopy, at about $2 \mathrm{~m}$ from the sunlit side. For the images taken in the

183 down part, a cooled white screen was used as background, that being placed behind of each monitored

184 tree to simplify the isolation of the canopy surface through image processing. For the images of the

185 upper part, the regions of sky were used as the background. Thermal images were analysed with the

186 software developed by García-Tejero et al. (2012). This software allows to work with up to three

187 sections for each analyzed image, to select the temperature range corresponding to pixels of the 
189 to the stem and the background (Figure. 1).

190 In order to normalize the thermal information and taking the absolute values of $T_{\mathrm{C}}$ as the starting point,

191 two thermal indexes were estimated: the difference between canopy and the surrounding air ( $\Delta T_{\text {canopy-air }}$ )

192 and the crop water stress index (CWSI); these being calculated as follows (Idso, 1981; Jackson et al., 193 1981):

194

$195 \Delta T_{\text {canopy-air }}=T_{C}-T_{\text {air }}$

$197 \quad C W S I=\frac{\Delta T-\Delta T w e t}{\Delta T d r y-\Delta T w e t}$

where $\Delta T_{\text {canopy-ari, }} \Delta T_{\text {dry }}$ and $\Delta T_{\text {wet }}$ is the difference between canopy and air temperature in the moment

200 of the measurement, $T_{\mathrm{c}}$ is the temperature of the canopy, $T_{\mathrm{ari}}$ is the temperature of the surrounding air,

201 and $\Delta T_{\text {dry }}$ and $\Delta T_{\text {wet }}$ are the difference between canopy and air temperature when the crop has the

202 stomata fully closed and when is fully transpiring, respectively.

204 To obtain the reference values of $\Delta T_{\text {wet }}$ we calculated the non-water stress baselines $\left(\Delta T_{\text {canopy-air }}=\mathrm{a}+\right.$ $205 \mathrm{~b}^{*} V P D$ ) according to Idso et al. (1981), and used a $\Delta T_{\text {dry }}$ value equal to $5^{\circ} \mathrm{C}$, as proposed by Jackson et 206 al. (1982). Non-water stress baselines were defined for two different moments of the day (08:30 and 207 12:00 GTM, respectively), i.e. when $T_{\mathrm{C}}$ readings were made. Moreover, as $T_{\mathrm{C}}$ readings were obtained 208 from two different areas of the tree (down and topside), these functions were defined for each location. 209 Thus, four relationships between VPD vs. $\triangle T_{\text {canopy-ari }}$ were estimated for each monitoring time (08:30 and

$21012: 00$ GTM) and parts of the canopy (at the bottom and top). In all cases, these relationships were 211 derived from the canopy temperature readings in FI trees.

212 Finally, sSoil water content was measured by using a Profile probe (Delta-T Devices Ltd., Cambridge,

$213 \underline{U}$ U), recording the volumetric soil water content $(\theta)$ values in the root zones of three trees per treatment.

214 Each access tube was installed at $0.5 \mathrm{~m}$ from the tree trunk, measuring the soil-water content at 10, 20,

21530 , and $40 \mathrm{~cm}$, coinciding the measurement days with those days in which the physiological 216 measurements were done. Previously, the Profile probe was calibrated in situ as it was described by

217 Fernández et al. (2011b).

219 2.4.- Statistical analysis

220 For each measurement day, an exploratory and descriptive analysis of physiological measurements and 221 canopy readings was made after applying a Levene's test to check the variance homogeneity of the 222 studied variables. Significant differences between irrigation treatments $(p \leq 0.05$ and $p \leq 0.01)$ in the 
studied variables were identified by applying a one way ANOVA and a Tukey's test for treatment separation, with the SPSS statistical software (SPSS Inc., 15.0 Statistical package; Chicago, IL, USA).

225 To evaluate the non-water stress baselines for each sampling time and canopy location, a linear correlation analysis was made $(n=8)$ with a covariance analysis at a confidence level of $95 \%$. That

227 allowed to compare the functions (slope and intercept) and evaluate significant differences.

228 To evaluate the relationships between variables, a linear correlation analysis between the thermal

229 indicators ( $T_{\mathrm{c}}, \Delta T_{\text {canopy-air }}$ and $\left.C W S /\right)$ and the physiological variables $\left(\psi_{\mathrm{st}}, \mathrm{g}_{\mathrm{s}}, A_{\mathrm{N}}\right.$ and $\left.E\right)$ and $\theta$ at the

230 different depths was made for each sampling time and location $(n=24)$. The obtained correlation

231 coefficients were used to identify both the best time and location to carry out $T_{\mathrm{C}}$ readings. This allowed

232 us to assess the reliability of the mentioned thermal indicators as a proxy for crop physiology traits.

233 Once selected the best moment of the day to carry out the $T_{\mathrm{c}}$ readings, and the most representative

234 thermal indicator, the obtained linear regressions for each sampling location in the canopy were

235 compared (slope and intercept) using a covariance analysis at a confidence level of $95 \%$.

\section{3.- Results and discussion}

\subsection{Meteorological conditions, irrigation events and physiological measurements}

Figure 2 shows the irrigation events applied in each irrigation treatment. According to the chosen irrigation strategies (more details in Padilla-Díaz et al. 2016), in Period 1 (DOY 98-124), Period 2 (DOY 146 to 173 ) and Period 3 (DOY 237 to 257) all the trees were daily irrigated to replace crop requirements. In Period 2 the $\mathrm{FI}$ trees received $102 \%$ of irrigation needs (IN), whereas $45 \mathrm{RDI}$ Tp and 45RDIcc trees received $90 \%$ and $79 \%$ of IN, respectively. In between Periods 2 and 3 (DOY 174 to 236), FI trees received $107 \%$ of $I N$, whereas both $45 R D I_{T P}$ and $45 R D I_{\text {Cc }}$ received $24 \%$ and $25 \%$ IN respectively, with two or three irrigation events per week. Finally, during Period 3 all trees were daily

249 Seasonal courses of main weather variables recorded at the two sampling times of the day are shown in

250 Figure. 3. The highest values of temperature and net radiation were recorded at the beginning of the 251 experimental period (June), while top values of relative humidity were recorded at the end (September).

252 Values of vapor pressure deficit were quite high all along the experimental period, especially at the 253 beginning.

254 The seasonal courses of $\psi_{\text {st }}$ and gas exchange measurements were in line with the irrigation strategies 255 applied in each treatment (Figure 4). At the beginning of the experimental period (DOY 169) no 256 differences between treatments were found for any physiological variable. This is in agreement with the 257 fact that during Period 2 all trees received irrigation amounts close to the irrigation needs (Figure 2).

258 At the beginning of the stress-increasing period (DOY 183, nine days after the end of Period 2) we 259 found a faster decrease in gas exchange than in $\psi_{\text {st. }}$. A similar behaviour was observed by Torres-Ruiz 260 etal. (2013) and Pérez-Martín et al. (2014) in 'Manzanilla' olive trees. They related this behaviour with 
261 the effective stomata control of plant water status in this species, mainly in the first stages of water 262 stress (Fernández et al., 1997; Fernández 2014a). Later, from DOY 183 to 225, stomatal conductance $263\left(g_{s}\right)$, net $\mathrm{CO}_{2}$ assimilation $\left(A_{N}\right)$ and consequently leaf transpiration $(E)$, decreased progressively in the

264 RDI trees. This is in accordance with those trees were receiving just ca. $25 \%$ of IN in that Period. The

265 lowest values of these three variables were recorded on DOY 218.

266 Later in the season, and in agreement with the greater water supplies of Period $3, g_{s}, A_{N}$ and $E$ values in

267 RDI trees became similar to those recorded in FI trees, showing a full recovery of the trees on that

268 period. However, at the beginning of this period, values of $\psi_{\text {st }}$ recovered quicker than those of gas

269 exchange related variables. This is also typical in olive (Fernández, 2013, Perez-Martin et al., 2014).

270 The Fl trees showed values of $\psi_{\mathrm{st}}, g_{\mathrm{s}}, A_{\mathrm{N}}$ and $E$ close to the maximum for olive trees under non-limiting

271 conditions (Diaz-Espejo et al., 2006), all along the experimental period.

272 Significant differences in $\psi_{\text {st }}$ among treatments were observed in between Periods 2 and 3 , when these

273 values were progressively descending in $45 \mathrm{RDI}$ trees till reaching a minimum value of $-4.4 \pm 0.1 \mathrm{MPa}$

274 on DOY 218 and 225. This descend was accompanied with a depletion in gas-exchange parameters,

275 being recorded the minimum values when $\psi_{\text {st }}$ was close to $-3 \mathrm{MPa}$. (Figure 4).

3.2. Diurnal evolution of canopy temperature and related thermal indices

278 Figure 5 shows the average of canopy temperature readings taken at the two sampling times and

279 locations, for the three irrigation treatments during the monitoring period. For all treatments and

280 sampling times, differences were observed between the down and the upper part. These differences

281 were especially remarkable at $08: 30 \mathrm{GMT}$, when values in the upper part were up to $5^{\circ} \mathrm{C}$ below those

282 from the down part. This could be due to heat transmission from the soil to the down part of the canopy

283 or to greater heat dissipation in the upper part because of the wind. The first differences between $\mathrm{Fl}$ and

284 RDI trees appeared on DOY 197, these differences being more evident at 08:30 GMT on the down part,

285 whereas, at 12:00 GMT the differences were significant in both sampling areas. Differences in $T_{\mathrm{C}}$

286 between treatments increased along the season, being greater at 12:00 than at 08:30 GMT, and in the

287 lower part of the canopy that at the upper part. Depending on the location and sampling time,

288 differences among treatments ranged from 2 to $6^{\circ} \mathrm{C}$.

289 Our results agree with those reported for other olive orchards of different locations and characteristics.

290 Sepulcré-Cantó et al. (2006) detected differences close to $2^{\circ} \mathrm{C}$ by using infrared sensors installed $1 \mathrm{~m}$ 291 above the olive crown. Poblete-Echeverría et al. (2016), in a study developed in 'Arbequina' trees,

292 registered temperature differences around $4-5^{\circ} \mathrm{C}$, at the moments of maximum stress level $\left(\Psi_{\mathrm{st}}<-5\right.$

$293 \mathrm{MPa}$ ). Other authors such as Testi et al. (2008) in Pistachio, García-Tejero et al. (2011) in citrus trees,

294 and García-Tejero (2016) in vines reported temperature differences of 2-6 ${ }^{\circ} \mathrm{C}$ between fully irrigated and 295 stressed trees.

296 It is noticeable that differences between treatments in $T_{\mathrm{c}}$ were detected when the lowest $g_{\mathrm{s}}$ values were

297 recorded (DOY 197 to 225 DOY, Figures 4 and 5). Nevertheless, $T_{c}$ readings in FI treatment showed a 
298 high variation, probably associated to differences in meteorological conditions during the sampling days.

299 As it has been previously stated, the effect of stomatal regulation (partial closure) under a mild or 300 moderate water stress is that leaf temperature trends to increase, because of a decrease in the heat 301 dissipated by transpiration (Jones et al., 2002; 2009; Jones and Vaughan, 2010). According to Jones et 302 al. (2009) and Jones and Vaughan (2010), there are many variables such as the radiation level, air 303 temperature, vapour pressure deficit, the relative humidity or the angle of the radiation incident on the 304 leaf surface that will influence decisively on the absolute value of $T_{c}$. Therefore all of them must be 305 taken into account when making an assessment of crop water status from thermal information. This 306 explains the difficulty of establishing a threshold value of $T_{\mathrm{C}}$ for irrigation scheduling and crop-water 307 status monitoring. This is a limitation of the thermal approach as compared to $\psi_{\mathrm{st}}$ or $g_{\mathrm{s}}$, variables for 308 which threshold values for water stress can be more easily established (Fernández et al. 2008b; 309 Moriana et al., 2012).

310 Once normalized the $T_{c}$ readings by estimating the difference between canopy and the surrounding air 311 ( $\Delta T_{\text {canopy-air }}$, we observed $\Delta T_{\text {canopy-air }}$ values below $0{ }^{\circ} \mathrm{C}$ for the $\mathrm{Fl}$ trees, especially at 12:00 GMT, and 312 with a temporal variation much less than detected for $T_{\mathrm{C}}$ readings (Figure 6). This is in line with the 313 results reported by Sepulcré-Cantó (2006) and Poblete-Echeverría (2016), from readings taken in 314 similar conditions. This corroborates what we have stated above for the thermal readings at 12:00 GMT 315 and in the down part of the canopy, these being the most informative in terms of tree water status. Thus,

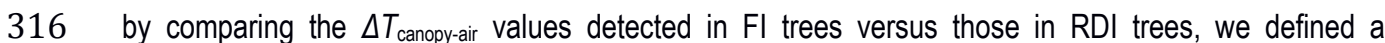
317 threshold value of $\Delta T_{\text {canopy-air }}=0{ }^{\circ} \mathrm{C}$, above which a severe water stress situation would be being 318 supported by the crop.

319 After using the methodology proposed by Idso et al. (1981) and Jackson et al. (1981) to derive non-

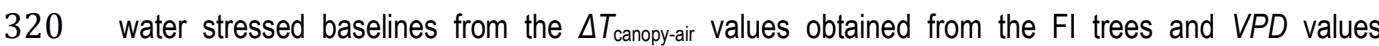
321 registered for each time and monitoring day, significant relationships were obtained for the four 322 sampling situations, especially for the measurements at 12:00 $\mathrm{h}$ (Table 1). For the readings taken at 323 12:00 GMT in the down part, the slope was similar to that obtained by other authors such as Berni et al. 324 (2009) in 'Arbequina' olive trees (-0.35) from measurements $1 \mathrm{~m}$ above the trees, although the intercept 325 point was different (2.08). According to these authors, the explanation of the low slopes derived from the 326 non-water stressed baselines would the small size of the olive leaves, which are very coupled to the 327 atmosphere (Villalobos et al., 2000) and because of the marked stomatal control even in full irrigated 328 trees, when the evaporative demand is very high. As a consequence of this slope, CWSI estimation in 329 olive trees is very much affected by errors in both the estimation of $T c$ and the measurement of $T_{\text {air }}$ 330 (Berni et al., 2009). More interesting were the reflections argued by these authors, when they compared 331 effect of net radiation and wind speed in the interception point, suggesting that the slopes obtained for 332 different non-water stressed baselines estimated from a theorist proposed model by them were very 333 similar to the obtained from empirical information; and the highest variations were observed in the 334 interception point. Similar results were reported Testi et al. (2008) in pistachio trees, evidencing that 
335 daily variations in net radiation resulted in parallel baselines, i.e. the slope of the baseline was not 336 affected.

337 Figure 7 shows the CWSI evolution calculated by using the non-water stressed baselines defined in

338 Table 1 according to the $T_{\mathrm{c}}$ values of $\mathrm{Fl}$. The seasonal course of this index was similar to that of

$339 \Delta T_{\text {canopy-air }}$ (Figures 6 and 7). The greatest differences in CWSI between treatments were reached from

340 DOY198 to DOY 225, especially at 12:00 GTM. The lowest CWSI values were found in the FI trees,

341 being around 0 (dimensionless), especially during the readings taken at 12:00 and at 08:30 GTM in the

342 down part. However, CWSI values derived from the thermal readings at 12:00 GMT in both parts of the

343 canopy were occasionally higher than $0^{\circ} \mathrm{C}$ in the $\mathrm{Fl}$ trees, which were under non-limiting soil water

344 conditions. This could be related to the sensitiveness of CWSI to weather conditions, e.g. solar radiation

345 (Agam et al., 2013), or to tree architecture (González-Dugo et al., 2014). In any case, this is a limitation

346 of CWSI that curtails its potential as a reliable index to schedule irrigation. Such limitation was not

347 detected for $\Delta T_{\text {canopy-air. }}$ The fact that threshold values for the assessment of the crop water status

348 cannot be easily derived from thermal readings is acknowledged as one of the main limitations of this

349 technique to schedule irrigation in commercial orchards.

350

351 3.3.- Relationships between the thermal information ${ }_{2}$-and versus physiological variables and soil-water 352 content

353 In the last few years, many works have been developed to optimize the use of thermography to assess

354 the crop-water status and to schedule irrigation (Jones et al., 2002; Leinonen and Jones, 2004),

355 reporting significant correlations between thermal information and other related physiological variables

356 (Berni et al., 2009; Poblete-Echeverría et al., 2014; Osroosh et al., 2016). In our case, relationships

357 between thermal and physiological data were derived to define the most efficient thermal index and the

358 best sampling time to assess the crop water status. Table 2 shows the Pearson's correlation coefficients

359 obtained for the relationships corresponding to the measurements taken at 08:30 and 12:00 GMT in the

360 lower and upper part. Regarding $T_{\mathrm{C}}$, the most significant correlations were obtained at 12:00 GTM,

361 these being very similar for both the readings in the down part and in the upper part. Moreover, a similar

362 robustness was observed for the relationships derived from the readings taken at 08:30 in the down

363 part. This did not apply to measurements from the upper part. Regarding the coefficients obtained for

$364 \Delta T_{\text {canopy-air }}$ and $C W S /$ with the physiological parameters, these were better than those for $T c$, especially

365 for the readings taken at 12:00 GMT. This indicates the feasibility and robustness of both thermal

366 indexes, especially $\Delta T_{\text {canopy-ar, }}$ because of its simplicity in comparison to CWSI.

367 Additionally, thermal information obtained at 8:30 and 12:00 GTM in the lower and upper part was

368 related to the soil-water content measurements registered at different depths (Table 3). On overall,

369 thermal data obtained at 10:30 GTM did not reflect with enough robustness the soil-water status, in

370 comparison to the relationships obtained by using the thermal information derived from the

371 measurements taken at 12:00 GTM. In this agreement, as $T_{C}$ as the related thermal indexes (CWSI and

Formatted: Font: Not Italic 
$\Delta T_{\text {canopy-air }}$ reported significant relationships with the $\theta$ obtained at different layers. Within the

373 measurements taken at 12:00 GTM, the best relationships were obtained when comparing the thermal

374 information derived from the images taken in the lower part, and within them, by using the readings of $\theta$

375 corresponding to the first soil layers (at 10 and $20 \mathrm{~cm}$ depth, respectively). These results would suggest

376 the possibility of stablishing deficit irrigation programmes combining the information obtained in the

377 three levels of the soil-plant-atmosphere system: weather data ( $T_{\text {air and VPD), soil }(\theta) \text { and plant }\left(T_{c} \text { and }\right.}$

378 the related thermal indexes).

379 Faking into account that In agreement with this, the most significant relationships between these thermal

380 indexes and physiological parameters were obtained from readings taken at 12:00 GMT. Different

381 functions were defined depending of measurements being taken in the down part or in the upper part

382 (Figure 8). One of the most remarkable findings was the coincidence of the threshold values determined

383 for $\Delta T_{\text {canopy-air }}$ and $C W S I$ in terms of $\psi_{\mathrm{st}}, C W S I$, and $A_{N}$. As it can be observed in Figure 8, taking into

384 account the readings obtained in the upside, $\Delta T_{\text {canopy-air }}$ close to zero would be associated with $\psi_{\mathrm{st}} \leq-3$

$385 \mathrm{MPa} ; g_{\mathrm{s}} \leq 0.1 \mathrm{~mol} \mathrm{~m}^{-2} \mathrm{~s}^{-1}$ and $A_{\mathrm{N}} \leq 8 \mu \mathrm{mol} \mathrm{m} \mathrm{m}^{-2} \mathrm{~s}^{-1}$, these values having been defined as indicators of 386 situations of severe water stress (Fernández et al., 2013, Díaz-Espejo et al., 2012; Pérez-Martín et al., 387 2014; Hernández-Santana et al., 2016; Padilla-Díaz et al., 2016; among others). Something similar 388 occurred taking as reference the values of $C W S I$, these being around 0.2 when $\Delta T_{\text {canopy-air }}$ was close to 389 zero.

390 When considering the readings from the down part, the defined threshold values for a moderate-to-

391 severe water stress for $\Delta T_{\text {canopy-air }}$ would be between 1.5 to $2{ }^{\circ} \mathrm{C}$, and between 0.4 to 0.5 in terms of 392 CWSI (Figure 8).

393 Likewise, the applicability of these relationships is reduced at farm level, because of their high variability 394 within the orchard crop (García-Tejero et al., 2016), being more advisable the use of threshold values 395 such as those derived from our results. In this regard, the robustness observed in the relationships 396 between $\Delta T_{\text {canopy-air }}$ and the studied physiological parameters would justify the use of this thermal index 397 stablishing a threshold value of $\Delta T_{\text {canopy-air }}$ close to zero when thermal readings are taken at 12:00 GTM 398 in the down part of the canopy.

399

400

401 Conclusions

402 Crop water monitoring by using thermal information in olive is highly dependent on the procedure of

403 thermal acquisition. This work demonstrates the sensitiveness of this technique to the monitoring 404 process; observing different results when measurements are taken at different hours and in different 405 parts of the tree. Owing to this phenomenon, it could be difficult to compare our results with other 406 obtained by using other kind of thermal sensors or also by applying different image processing and 407 capture. In spite of this constraint, on overall, our result suggest that as $\Delta T_{\text {canopy-air }}$ as $C W S I$ can be 408 considered as robust indicators of crop-water status, as it was demonstrated by the relationships 
derived from monitored the physiological variables such as $g_{\mathrm{s}}$ or $\psi_{\text {st. }}$. In line with this conclusion, $\Delta T_{\text {canopy- }}$ air would allow stablishing deficit irrigations scheduling exclusively by using thermal information, not

411 being necessary the use of relationships with other physiological parameters; and taking a threshold

412 value close to zero, as the point above which a moderate stress situation is being supported by the

413 crop. Likewise, as $\Delta T_{\text {canopy-air }}$ as $C W S$ I showed significant relationships with crop water potential and gas

414 exchange measurements, especially with the readings taken at 12:30 GTM; being possible to estimate

415 these values throughout thermal information. Moreover, these thermal indexes showed significant

416 relationships with the soil water content at different depths, especially by using the soil moisture

417 readings taken in the first $20 \mathrm{~cm}$, evidencing the possibility of define irrigation programming based on

418 measurements of crop and soil water status. Nevertheless, these relationships could not be assumed

419 for other different situations, cultivars, image capturing and processing, being advisable to define

420 specific functions in the case of estimating the crop-water status or gas-exchange levels exclusively

421 using thermal information.

422

423

424

\section{Acknowledgements}

425 The author I. Garcia-Tejero has a contract co-financed by the Operational Programme of the European

426 Social Fund (ESF) 2007-2013 "Andalucia is moving with Europe". This work is funded by the MINECO

427 (Spanish Ministry of Economy and Competitiveness, research project AGL2012-34544; C.M. Padilla-

428 Díaz was supported by a predoctoral contract grant BES-2013-065380). Thanks to Antonio Montero for

429 his help during the field work. Thanks to the owners of Internacional Oli-varera, S.A.U. (Interoliva), for

430 allowing us to make the experiments in the Sanabria orchard.

\section{References}

434 Allen, R.G., Pereira, L.S., Raes, D., Smith, M. 1998 Crop evapotranspiration - guidelines for computing crop water requirements. FAO Irrigation and drainage paper 56. Food and Agriculture Organization, Rome.

Baluja, J., Diago, M.P., Balda, P., Zorer, R., Meggio, F., Morales, F., Tardaguila, J. 2012. Assessment of vineyard water status variability by termal and multispectral imagery using an unmanned aerial vehicle (UAV). Irrig. Sci. 30, 511-522.

Bellvert, J., Zarco-Tejada, P.J., Fereres, E., Girona, J. 2014. Mapping crop water stress index in a 'Pinot-noir' vineyard: comparing ground measurements with thermal remote sensing imagery from an unmanned aerial vehicle. Precision Agric. J. 15, 361-376.

Berni, J.A.J., Zarco-Tejada, P.J., Sepulcre-Canto, G., Fereres, E., Villalobos, F. 2009. Mapping canopy Formatted: Spanish (Spain International Sort) conductance and CWSI in olive orchards using high resolution thermal remote sensing imagery. Remote Sens. Environ. 113, 2380-2388. 
Costa, J.M., Ortuño, M.F., Lopes, C.M., Chaves, M.M. 2012. Grapevine varieties exhibiting differences in stomatal response to water deficit. Funct. Plant Biol. 39, 179-189.

Costa, J.M., Grant, O.M., Chaves, M.M. 2013. Thermography to explore plant-environment interactions. J. Exp. Bot. 64, 3937-3949.

Cohen, Y., Alchanatis, V., Meron, M., Saranga, Y. and Tsipris, J. 2005. Estimation of leaf water potential by thermal imagery and spatial analysis. J. Exp. Bot. 56:1843-1852.

Cohen, Y., Alchanatis, V., Sela, E., Saranga, Y., Cohen, S., Meron, M., Bosak, A., Tsipris, J., Ostrovsky, V., Orolov, V., Levi, A., Brikman, R. 2015. Crop water status estimation using thermography: multi-year mode I development using ground-based thermal images. Precision Agric. 16, 311 329.

Cuevas, M.V., Torres-Ruiz, J.M., Alvarez, R., Jiménez, M.D., Cuerva, J., Fernández, J.E. 2010 Assessment of trunk diameter variation dderived indices as water stress indicators in mature olive trees. Agric Water Manage. 97, 1293-1302.

Cuevas, M.V., Martín-Palomo, M.J., Díaz-Espejo, A., Torres-Ruiz, J.M., Rodriguez-Dominguez, C.M., Perez-Martin, A., Pino-Mejías, R., Fernández, J.E. 2013. Assessing water stress in a hedgerow olive orchard from sap flow and trunk diameter measurements. Irrig Sci. 31, 729-746.

Diaz-Espejo, A., Buckley, T.N., Sperry, J.S., Cuevas, M.V., de Cires, A., Elsayed-Farag, S., MartinPalomo, M.J., Muriel, J.L., Perez-Martin, A., Rodriguez-Dominguez, C.M., Rubio-Casal, A.E., Torres-Ruiz, J.M., Fernández, J.E. 2012. Steps toward an improvement in process-based models of water use by fruit trees: a case study in olive. Agric. Water Manage. 114, 37-49.

Diaz-Espejo, A., Walcroft, A.S., Fernandez, J.E., Hafidi, B., Palomo, M.J., Giron, I.F. 2006. Modeling photosynthesis in olive leaves under drought conditions. Tree Physiology 26, 1445-1456.

Egea, G., Díaz-Espejo, A., Férnández, J.E. 2016. Soil moisture dynamics in a hedgerow olive orchard under well-watered and deficit irrigation regimes: Assessment, prediction and scenario analysis. Agric Water Manage. 164, 197-211.

Ennajeh, M., Tounekti, T., Vadel, A.M., Khemira, H., Cochard, H. 2008. Water relations and droughtinduced embolism in olive (Olea europaea) varieties 'Meski' and 'Chemlali' during severe drought. Tree Physiology 28, 971-976.

ESYRCE, 2014. Encuesta sobre superficies y Rendimientos. Spanish Ministry of Agriculture, Food and Environment. http://www.magrama.gob.es/es/estadistica/temas/estadisticasagrarias/agricultura/esyrce/

FAOSTAT, 2015. Food and Agriculture Division of United Nations. Statistic division. http://faostat3.fao.org/home/E

Fereres, E., Soriano, M.A. 2007. Deficit irrigation for reducing agricultural water use. J Exp Bot 58,147159.

Fernández, J.E. 2014a. Understanding olive adaptation to abiotic stresses as a tool to increase crop performance. Environ. Exp. Bot. 103, 158-179. 
Fernández, J.E. 2014b. Plant-based sensing to monitor water stress: Applicability to commercial 484 orchards. Agric. Water Manage. 142, 99-109.

Fernández, J.E., Diaz-Espejo, A., d'Andria, R., Sebastiani, L., Tognetti, R. 2008b. Potential and limitations of improving olive orchard design and management through modelling. Plant Biosys. 142:130-137.

Fernández, J.E., Diaz-Espejo, A., Infante, J.M., Durán, P., Palomo, M.J., Chamorro, V., Girón, I.F., Villagarcía, L. 2006 Water relations and gas exchange in olive trees under regulated deficit irrigation and partial rootzone drying. Plant Soil 284:271-287.

Fernández, J.E., Green, S.R., Caspari, H.W., Diaz-Espejo, A., Cuevas, M.V. 2008a. The use of sap flow measurements for scheduling irrigation in olive, apple and Asian pear trees and in grapevines. Plant Soil 305:91-104.

Fernández, J.E., Moreno, F., Girón, I.F., Blázquez, O.M., 1997. Stomatal control of water use in olive tree leaves. Plant and Soil 190, 179-192.

Fernández, J.E., Rodriguez-Dominguez, C.M., Perez-Martin, A., Zimmermann, U., Rüger, S., MartínPalomo, M.J., Torres-Ruiz, J.M., Cuevas, M.V., Sann, C., Ehrenberger, W., Diaz-Espejo, A., 2011a. Online-monitoring of tree water stress in a hedgerow olive orchard using the leaf patch clamp pressure probe. Agric. Water Manage. 100, 25-35.

Fernández, J.E., Moreno, F., Martín-Palomo, M.J., Cuevas, M.V., Torres-Ruiz, J.M., Moriana, A. 2011b. Combining sap flow and trunk diameter measurements to assess water needs in mature olive orchards. Environ. Exp. Bot. 72, 330-338.

Fernández, J.E., Perez-Martin, A., Torres-Ruiz, J.M., Cuevas, M.V.,Rodriguez-Dominguez, C.M., Elsayed-Farag, S., Morales-Sillero, A., García, J.M., Hernandez-Santana, V., Diaz-Espejo, A., 2013. A regulated deficit irrigation strategy for hedgerow olive orchards with high plant density. Plant Soil 372, 279-295.

García-Tejero, I., Durán-Zuazo, V.H., Muriel-Fernández, J.L., Jiménez-Bocanegra, J.A. 2011. Linking canopy temperature and trunk diameter fluctuations with other physiological water status tools for irrigation scheduling in citrus orchards. Functional Plant Biology 38, 1-12.

García-Tejero, I., Durán-Zuazo, V.H., Arriaga, J., Hernández, A., Vélez, L.M., Muriel-Fernández, J.L. 2012. Approach to assess infrared thermal imaging of almond trees under water-stress conditions. Fruits, 67, 463-474.

García-Tejero, I.F., Muriel-Fernández, J.L., Durán-Zuazo, V.H., Arriaga, J. 2013. Uso eficiente del agua en la agricultura. IFAPA-CAPDR. 94 pp.

García-Tejero, I.F., Costa, J.M., Egipto, R., Lima, R.S.N., Durán, V.H., Lópes, C., Chaves, M.M. 2016. Thermal data to monitor crop-water status in irrigated Mediterranean viticulture. Agric. Water Manage. 2016. (Accepted)

Geerts, S., Raes, D. 2009. Deficit irrigation as an on farm strategy to maximize crop water productivity in dry areas. Agric Water Manag. 96, 1275-1284
Formatted: English (United

Kingdom)

Formatted: English (United Kingdom)

Formatted: English (United Kingdom)

Formatted: English (Canada)

Formatted: English (Canada)

Formatted: Spanish (Spain, International Sort)

Formatted: English (United

Kingdom)

Formatted: English (United

Kingdom) 
Gómez-del-Campo, M., 2013. Summer deficit-irrigation strategies in a hedgerow olive orchard cv.

'Arbequina': effect on fruit characteristics and yield. Irrig. Sci. 31, 259-269.

522 González-Dugo, V., Zarco-Tejada, P.J., Berni, J.A.J., Suarez, L., Goldhamer, D.A., Fereres, E. 2012.

523

524

525

526

527

528

529

530

531

532

533

534

535

536

537

538

539

540

541

542

543

544

545

546

547

548

549

550

551

552

553

554

555

556
Almond tree canopy temperature reveals intra-crown variability that is water stress-dependent. Agric. For. Meteorol. 154-155, 156-165.

Gonzalez-Dugo, V., Zarco-Tejada, P., Fereres, E. 2014. Applicability and limitations of using the crop water stress index as an indicator of water deficits in citrus orchards. Agric. For. Meteorol. 198199, 94-104.

Grant, O.M., Chaves, M.M., Jones, H.G., 2006. Optimizing thermal imaging as a technique for detecting stomatal closure induced by drought stress under greenhouse conditions Physiol. Plant. 127, 507-518.

Idso, S.B., Jackson, R.D., Pinter, P.J.J., Reginato, R.J., Hatfield, J.L. 1981. Normalizing the stress degree-day parameter for environmental variability. Agric. Meteorol. 24, 45-55.

Iniesta, F., Testi, L., Orgaz, F., Villalobos, F.J. (2009). The effects of regulated and continuous deficit irrigation on the water use, growth and yield of olive trees. Eur. J. Agron. 30, 258-265.

IPCC, 2014. Cambio climático 2014. Impactos, adaptación y vulnerabilidad. 40 pp. Available at: https://www.ipcc.ch/pdf/assessment-report/ar5/wg2/ar5_wgll_spm_es.pdf.

Jackson, R.D., Idso, S.B., Reginato, R.J., Pinter, P.J. 1981. Canopy temperature as a crop water-stress indicator. Water Resources Res. 17, 1133-1138.

Jackson, R. 1982. Canopy temperature and crop water stress. Adv. Irrig. 1, 43-85.

Jones, H.G. 1999. Use of infrared thermometry for estimation of stomatal conductance as a possible aid to irrigation scheduling. Agric. Forest Meteorol. 95, 139-149.

Jones, H.G., Stoll, M., Santos, T., de Sousa, C., Chaves, M.M., Grant, O.M. 2002. Use of infra-red thermography for monitoring stomatal closure in the field: application to the grapevine. J. Exp. Bot. 53, 2249-2260.

Jones, H.G. 2004. Irrigation scheduling: advantages and pitfalls of plant-based methods. J. Exp. Bot. $55,2427-2436$.

Jones H.G., Serraj, R., Loveys, B.R., Xiong, L., Wheaton, A., Price, A.H. 2009. Thermal infrared imaging of crop canopies for the remote diagnosis and quantification of plant responses to water stress in the field. Functional Plant Biology 36, 978-979.

Leinonen, I., Jones, H.G. 2004. Combining thermal and visible imagery for estimating canopy temperature and identifying plant stress. J. Exp. Bot. 55(401):1423-1431.

MAGRAMA (Spanish Agricultural and Environment Ministry) 2016. Yearbook of Agricultural Statistics 2014.

Martín-Vertedor, A.I., Pérez Rodríguez, J.M., Losada, H.P., Castiel, E.F. 2011. Interactive responses to water deficits and crop load in olive (Olea europea L., cv. Morisca). Growth and water relations. Agric. Water Manage. 98, 941-949.
Formatted: English (United

Kingdom)

Formatted: English (United

Kingdom)

Formatted: No underline, Font color: Custom Color $(\operatorname{RGB}(0,0,10))$ Spanish (Spain, International Sort) 

plants in response to progressive drought: stomatal conductance as a reference parameter. Ann. Bot. 89, 895-905

Möller, M., Alchanatis, V., Cohen, Y., Meron, M., Tsipris, J., Naor, A., Ostrovsky, V., ,Sprintsin, M., Cohen, S. 2007. Use of thermal and visible imagery for estimating crop water status of irrigated grapevine. J. Exp. Bot. 58, 827-838. DOI: 10.1093/jxb/erl115.

563 Moriana, A., Girón, I.F., Martín-Palomo, M.J., Conejero, W., Ortuño, M.F., Torrecillas, A., Moreno, F. 564 2010. New approach for olive trees irrigation scheduling using trunk diameter sensors. Agric. Water Manage. 97, 1822-1828. Midday stem water potential as a useful tool for estimating irriagtion requirements in olive trees. Agricultural Water Management 112, 43-54.

Osroosh, Y., Peters, R.T., Campbell, C.S. 2016. Daylight crop water stress index for continuous monitoring of water status in apple trees. Irrig. Sci, 34, 209-219.

Padilla-Díaz, C.M., Rodriguez-Dominguez, C.M., Hernandez-Santana, V., Perez-Martin A., Fernández, J.E. 2016. Scheduling regulated deficit irrigation in a hedgerow olive orchard from leaf turgor pressure related measurements. Agric. Water Manage. 164, 28-37.

Perez-Martin, A., Michelazzo, C., Torres-Ruiz, J.M., Flexas, J., Fernández, J.E., Sebastiani, L., DiazEspejo, A. 2014. Regulation of photosynthesis and stomatal and mesophyll conductance under water stress and recovery in olive trees: correlation with gene expression of carbonic anhydrase and aquaporins. J. Exp. Bot. 65, 3143-3156.

Poblete-Echeverría, C., Ortega-Farías, S., Zúñiga, M. 2014. Use of infrared thermography on canopies as indicator of water stress in Arbequina olive orchards. Acta Hort, 1057, 399-404.

Poblete-Echeverría, C., Sepúlveda-Reyes, D., Ortega-Farias, S., Zúñiga, M., Fuentes, S. 2016. PLant wáter stress detection based on aerial and terrestrial infrered thermography: a study case from vineyard and olive orchard. Acta Hort 1112, 141-146

Pou, A., Diago, M.P., Medrano, H., Baluja, J., Tardaguila, J. 2014. Validation of thermal indices for water stress status identification in grapevine. Agric. Water Manage. 134, 60-72.

\section{Rius X, Lacarte JM (015 La revolución del olivar. El cultivo en seto, $2^{\text {nd }}$ Ed. Barcelona}

Ruiz-Sanchez, M.C., Domingo, R., Castel, J.R. 2010 Review. Deficit irrigation in fruit trees and vines in Spain. Span J Agric Res 8, S5-S20.

Sepulcre-Cantó, G., Zarco-Tejada, P.J., Jiménez-Muñoz, J.C., Sobrino, J.A., de Miguel, E., Villalobos, F.J. 2006. Detection of water stress in an olive orchard with thermal remote sensing imagery. Agric. For. Meteorol. 136, 31-44.

Testi, L., Goldhamer, D.A., Iniesta, F., Salinas, M. 2008. Crop water stress index is a sensitive water stress indicator in pistachio trees. Irrig. Sci. 26,395-405. 
593 Torres-Ruiz, J.M., Diaz-Espejo, A., Morales-Sillero, A., Martín-Palomo, M.J., Mayr, S., Beikircher, B., 594 Fernández, J.E. 2013a. Shoot hydraulic characteristics, plant water status and stomatal 595 response in olive trees under different soil water conditions. Plant and Soil 373, 77-87.

596 USDA 2010 Keys to soil taxonomy (11th Edition). United States Department of Agriculture, Natural 597 Resource Conservation Service, $334 \mathrm{pp}$

598 Zimmerman, D., Reuss, R., Westhoff, M., Geßner, P., Bauer, W., Bamberg, E., Bentrup, F.W., 599 Zimmermann, U. 2008. A novel, non-invasive, online-monitoring, versatile and easy plant-based 600 probe for measuring leaf water status. J. Exp. Bot. 59, 3157-3167

601

602

603

604

605

606

607

608

609

610

611

612

613

614

615

616

617

618

619

620

621

622

623

624

625

626

627

628

629 
TABLES

631 Table 1. Fitted parameters for the baselines from non-stressed trees $\left(\Delta T_{\text {canopy-air }}=\mathrm{a}+\mathrm{b}^{*} V P D\right)$.

632 Data obtained for the DOY 169 to $253(n=8)$.

\begin{tabular}{lllll}
\hline GTM & Side & Slope $\left({ }^{\circ} \mathbf{C ~} \mathbf{~ P a}^{-1}\right)$ & Intercept $\left({ }^{\circ} \mathbf{C}\right)$ & $\mathbf{R}^{2}$ \\
\hline \multirow{2}{*}{$\mathbf{0 8 : 3 0}$} & Down & -1.92 & 5.65 & 0.76 \\
& Upper & -1.74 & 2.08 & 0.87 \\
\multirow{2}{*}{ 12:00 } & Down & -0.39 & 0.95 & 0.82 \\
& Upper & -0.67 & 0.09 & 0.87 \\
\hline
\end{tabular}

634

Table 2. Pearson's correlation coefficients between thermal indicators and physiological variables at the two sampling times and sampled canopy location.

\begin{tabular}{|c|c|c|c|c|c|c|}
\hline GMT & location & Thermal Indicator & $\psi_{\text {st }}$ & $A_{\mathrm{N}}$ & $g_{\mathrm{s}}$ & $E$ \\
\hline \multirow{6}{*}{$10: 30$} & \multirow{3}{*}{ Down } & $T_{\mathrm{C}}$ & $-0.61^{* *}$ & $-0.74^{* *}$ & $-0.74^{* *}$ & $-0.53^{* \star}$ \\
\hline & & $\Delta T_{\text {canopy-air }}$ & $-0.42^{*}$ & ns & $-0.41^{*}$ & $-0.55^{\star *}$ \\
\hline & & CWSI & $-0.66^{* *}$ & $-0.61^{* *}$ & $-0.69^{* *}$ & $-0.71^{* *}$ \\
\hline & \multirow{3}{*}{ Up } & $T_{\mathrm{C}}$ & ns & $-0.50^{*}$ & $-0.53^{* *}$ & ns \\
\hline & & $\Delta T_{\text {canopy-air }}$ & ns & ns & ns & ns \\
\hline & & CWSI & ns & ns & ns & ns \\
\hline \multirow{6}{*}{$12: 30$} & & $T_{\mathrm{C}}$ & $-0.57^{* *}$ & $-0.68^{* *}$ & $-0.65^{\star *}$ & $-0.46^{*}$ \\
\hline & Down & $\Delta T_{\text {canopy-air }}$ & $-0.78^{* *}$ & $-0.81^{* *}$ & $-0.80^{* *}$ & $-0.78^{* *}$ \\
\hline & & CWSI & $-0.74^{* *}$ & $-0.83^{* *}$ & $-0.80^{* *}$ & $-0.70^{* *}$ \\
\hline & \multirow{3}{*}{ Up } & $T_{\mathrm{C}}$ & $-0.57^{* *}$ & $-0.70^{* *}$ & $-0.65^{* *}$ & $-0.48^{*}$ \\
\hline & & $\Delta T_{\text {canopy-air }}$ & $-0.83^{* *}$ & $-0.83^{* *}$ & $-0.78^{* *}$ & $-0.81^{* *}$ \\
\hline & & CWSI & $-0.71^{\text {** }}$ & $-0.80^{* *}$ & $-0.77^{* *}$ & $-0.70^{* *}$ \\
\hline
\end{tabular}

$636 \Psi_{\text {st }}$, stem-water potential;; $A_{N}$, net-photosynthesis; $g_{\mathrm{s}}$, stomatal conductance to water vapour; $E$,

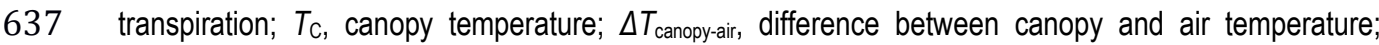

638 CWSI, crop-water stress index. ns, no significant relationships; * and ** evidence significant correlations

639 at 95 and $99 \%$, respectively.

640

641

642

643

644

645

646

647

648

649 
Table 3. Pearson's correlation coefficients between thermal indicators obtained at the two sampling times and sampled canopy location; and the volumetric soil-water content $\left(\theta, \mathrm{m}^{3} \mathrm{~m}^{-3}\right)$ measured at different depths $(10,20,30$ and $40 \mathrm{~cm}$, respectively).

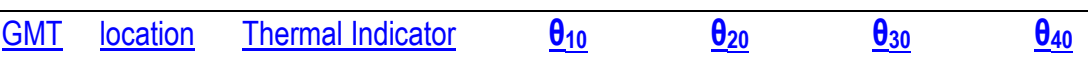

\begin{tabular}{|c|c|c|c|c|c|}
\hline & $\underline{T_{\mathrm{C}}}$ & $-0.58^{* *}$ & $-0.66^{* *}$ & $\underline{-0.52^{*}}$ & $\underline{-0.48^{*}}$ \\
\hline Down & $\Delta T_{\text {canopy-air }}$ & $\underline{\text { ns }}$ & $\underline{\text { ns }}$ & $\underline{\mathrm{ns}}$ & $\underline{\mathrm{nS}}$ \\
\hline
\end{tabular}

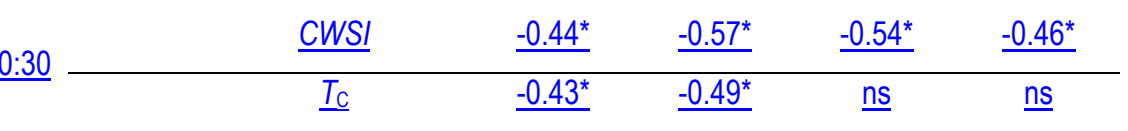

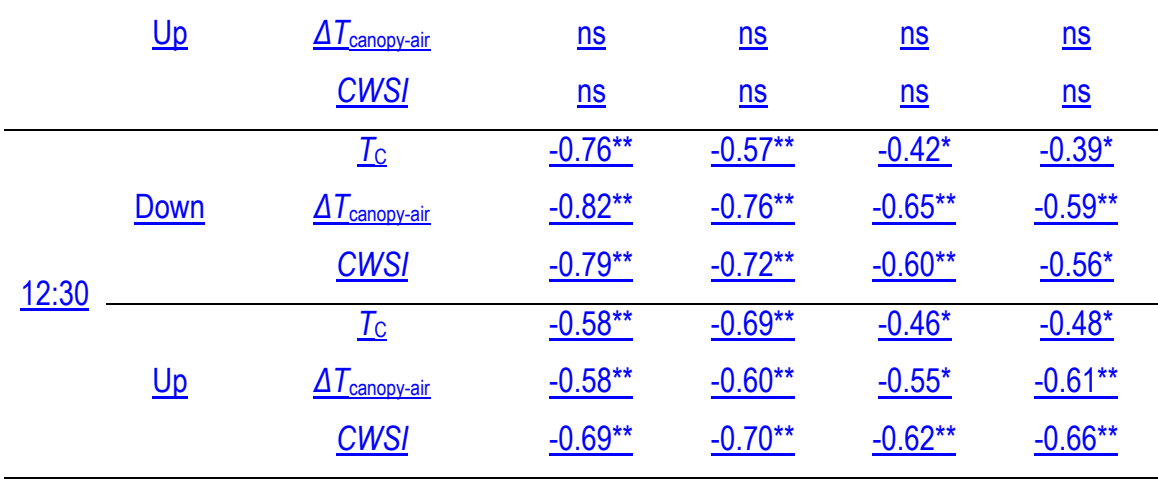

Ic, canopy temperature; $\Delta T_{\text {canopy-air, difference between canopy and air temperature; } C W S I \text {, crop-water }}$

658

659

660

661

662

663

664

665

666

667

668

669

670

671

672 
675

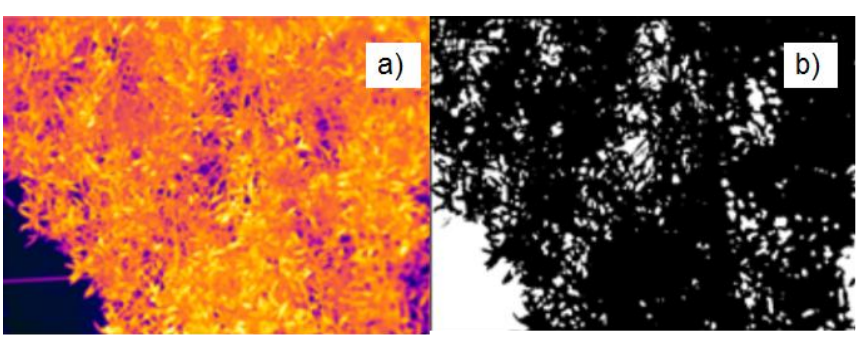

Figure 1. False colored image of downside olive tree (a) and post-processing image (monochrome image) representing in black the areas corresponding to pixels of leaves (b). This process allows deleting those pixels corresponding to branches, stem and the background (all these areas in white).

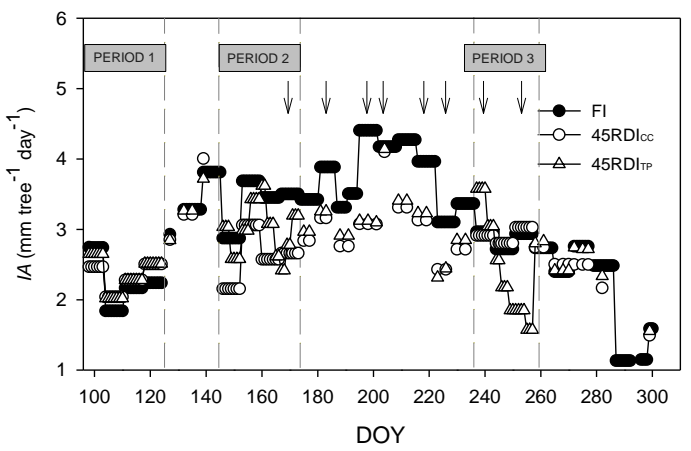

Figure 2. Irrigation applied (IA) in each irrigation treatment: full-irrigated (FI), crop-coefficient regulated deficit irrigation (45RDIcc), regulated deficit irrigation based on turgor pressure related measurements (45RDITP). Arrows down show the days on which the thermal measurements were made..
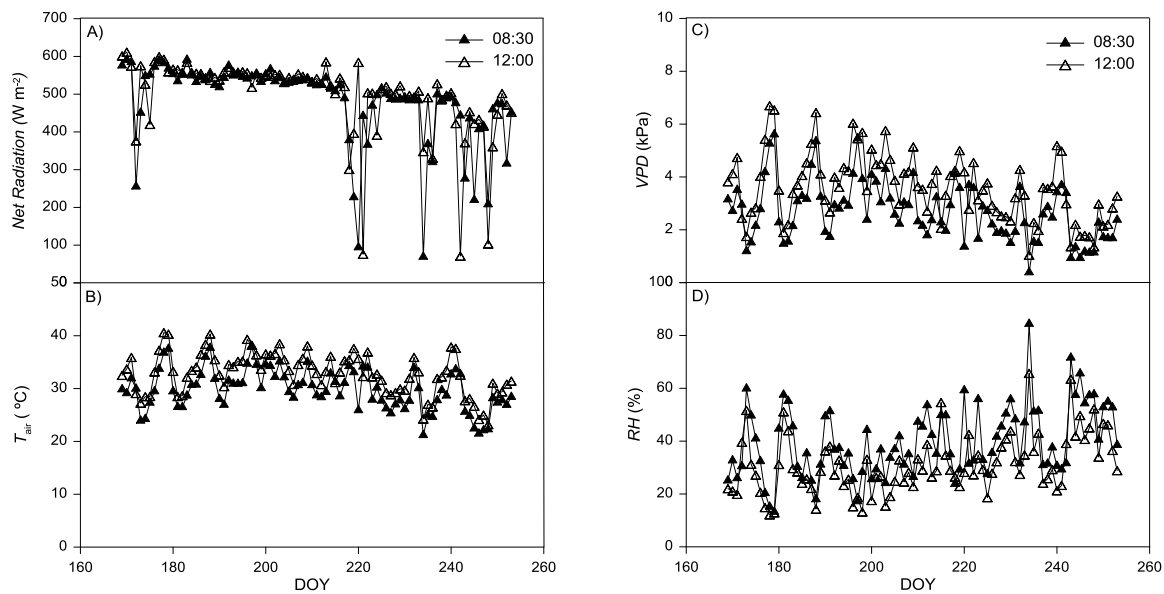

Figure 3. Seasonal course of net radiation (A), air temperature (B), vapour pressure deficit (C) and relative humidity (D), measured at 08:30 and 12:00 GMT. 

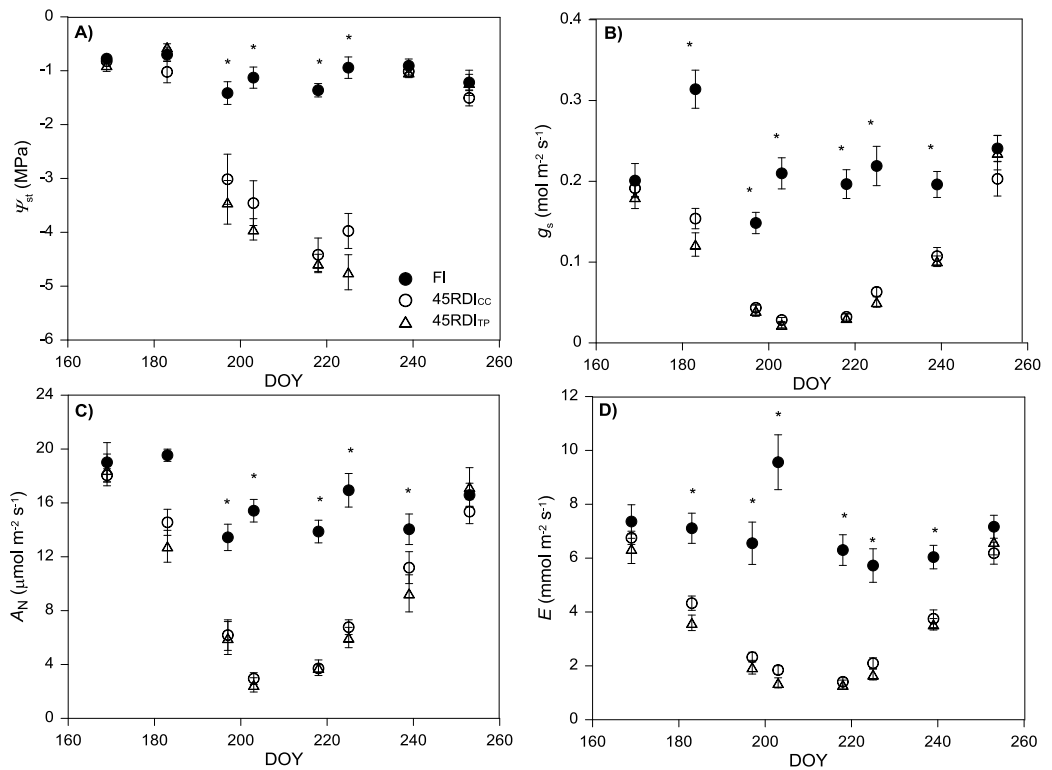

Figure 4. Seasonal course of stem water potential $\left(\psi_{\mathrm{st}}\right)(\mathrm{a})$, stomatal conductance $\left(g_{\mathrm{s}}\right)(\mathrm{b})$, net $\mathrm{CO}_{2}$ assimilation $\left(A_{N}\right)(c)$, and transpiration $(E)(d)$, measured in trees of the three irrigation treatments. * shows significant differences between $\mathrm{FI}$ and $\mathrm{RDI}$ trees $(\mathrm{p}<0.05)$. Each point corresponds to the average value
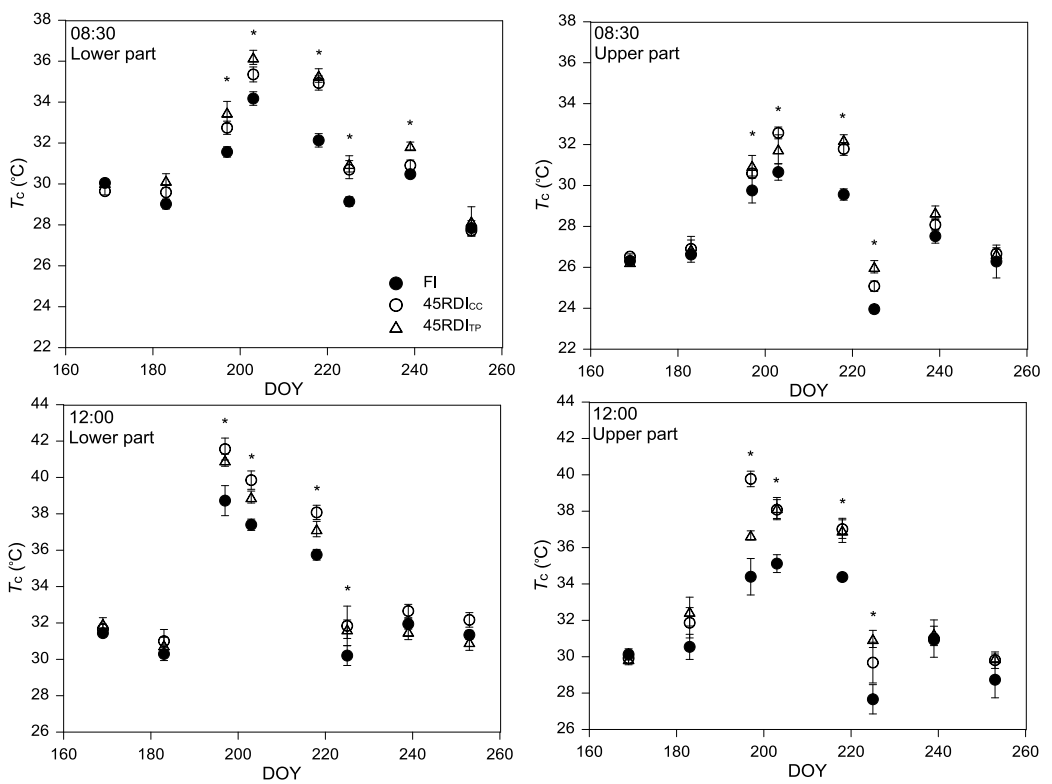

695 Figure 5. Seasonal evolution of the canopy temperature $\left(T_{c}\right)$ measured at the two times (08:30

696 and 12:00 GTM) and sampling locations in the canopy (lower and upper part), in trees of the 697 three irrigation treatments. * shows significant differences between $\mathrm{FI}$ and RDI treatments $(\mathrm{p}<0.05)$.

698 Each point corresponds to the average value for each treatment $(n=8)$. Vertical bars represent the 699 standard error of the mean. 

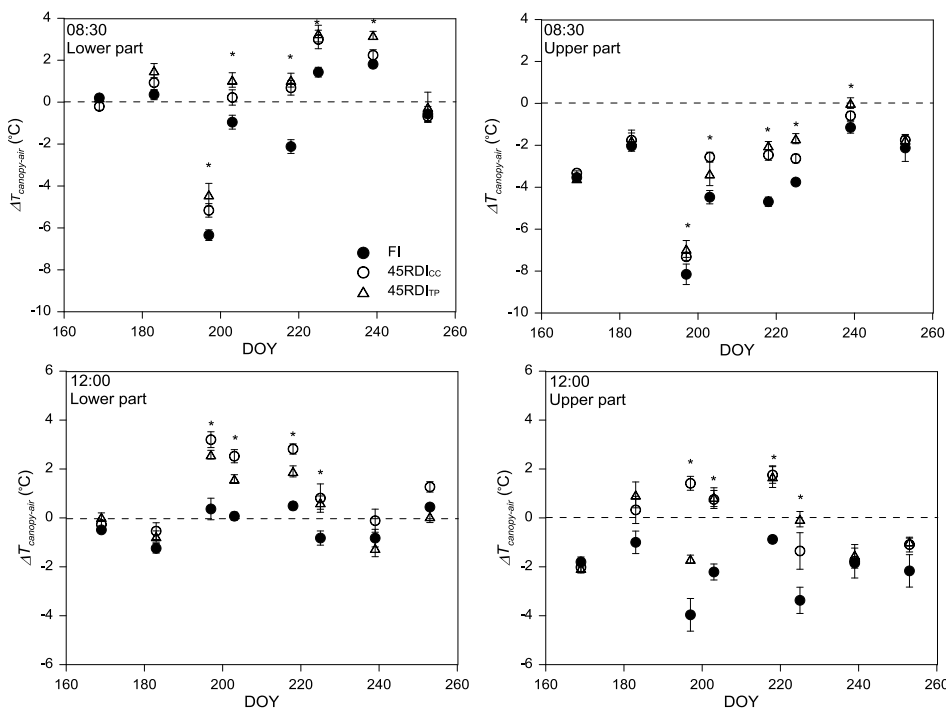

Figure 6. Seasonal evolution of the difference between canopy and air temperature ( $\left.\Delta T_{\text {canopy-air }}\right)$ measured at the two times (08:30 and 12:00 GTM) and sampling locations in the canopy (lower and upper part), in trees of the three irrigation treatments. * shows significant differences between FI and RDI treatments $(p<0.05)$. Each point corresponds to the average value for each treatment $(n=8)$. Vertical bars represent the standard error of the mean.

707
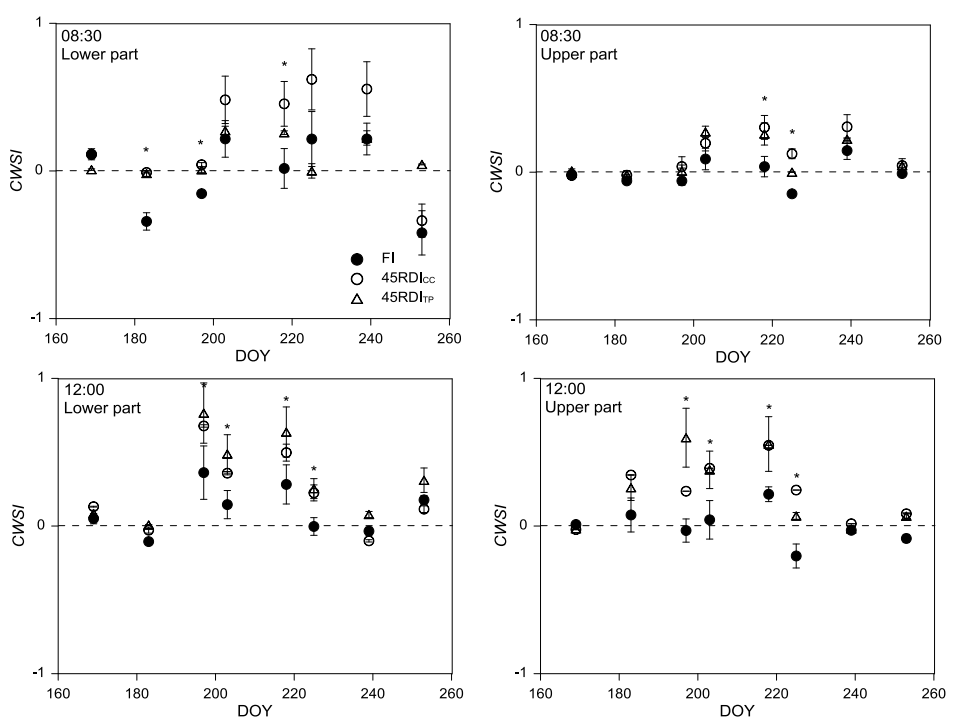

Figure 7. Seasonal evolution of the Crop Water Stress Index (CWSI) measured at the two times (08:30 and 12:00 GTM) and sampling locations in the canopy (lower and upper part), in trees of

711 the three irrigation treatments. * shows significant differences between FI and RDI treatments

$712(p<0.05)$. Each point corresponds to the average value for each treatment $(n=8)$. Vertical bars represent the standard error of the mean. 

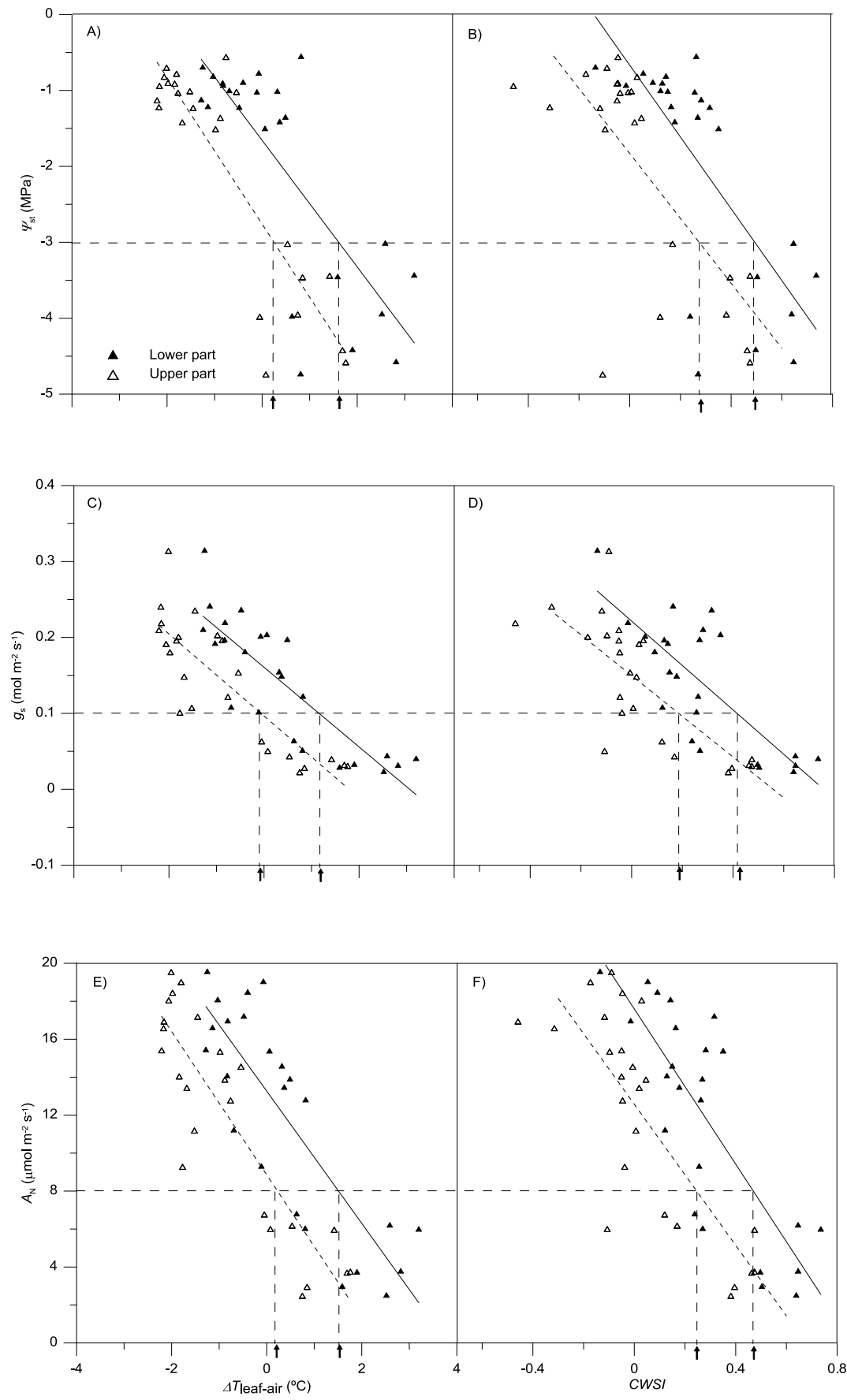

716 Figure 8. Linear regressions between the difference between canopy and air temperature

$717\left(\Delta T_{\text {canopy-air }}\right)$ and the crop-water stress index (CWSI, dimensionless) with the stem-water potential

$718\left(\boldsymbol{\Psi}_{\mathrm{st}}\right)$, stomatal conductance $\left(g_{\mathrm{s}}\right)$ and net $\mathrm{CO}_{2}$ assimilation $\left(A_{\mathrm{n}}\right)$, using the readings taken at 12:00 719 in the lower part of the canopy $(\boldsymbol{\Lambda})$ and in the upper part $(\Delta)$. 
Click here to download Tables: Table 1.docx

Table 1. Fitted parameters for the baselines from non-stressed trees $\left(\Delta T_{\text {canopy-air }}=a+b^{*} V P D\right)$. Data obtained for the DOY 169 to $253(n=8)$.

\begin{tabular}{lllll}
\hline GTM & Side & Slope $\left({ }^{\circ} \mathbf{C ~} \mathbf{~ P a}^{-1}\right)$ & Intercept $\left({ }^{\circ} \mathbf{C}\right)$ & $\mathbf{R}^{2}$ \\
\hline \multirow{2}{*}{$\mathbf{0 8 : 3 0}$} & Down & -1.92 & 5.65 & 0.76 \\
& Upper & -1.74 & 2.08 & 0.87 \\
\multirow{2}{12:00}{} & Down & -0.39 & 0.95 & 0.82 \\
& Upper & -0.67 & 0.09 & 0.87 \\
\hline
\end{tabular}


Table 2. Pearson's correlation coefficients between thermal indicators and physiological variables at the two sampling times and sampled canopy location.

\begin{tabular}{|c|c|c|c|c|c|c|}
\hline GMT & location & Thermal Indicator & $\psi_{\text {st }}$ & $A_{N}$ & $g_{\mathrm{s}}$ & $E$ \\
\hline \multirow{6}{*}{$10: 30$} & \multirow{3}{*}{ Down } & $T_{\mathrm{C}}$ & $-0.61^{* *}$ & $-0.74^{* *}$ & $-0.74^{* *}$ & $-0.53^{* *}$ \\
\hline & & $\Delta T_{\text {canopy-air }}$ & $-0.42^{*}$ & ns & $-0.41^{*}$ & $-0.55^{* *}$ \\
\hline & & CWSI & $-0.66^{* *}$ & $-0.61^{* *}$ & $-0.69^{* *}$ & $-0.71^{* *}$ \\
\hline & \multirow{3}{*}{ Up } & $T_{\mathrm{C}}$ & ns & $-0.50^{*}$ & $-0.53^{* *}$ & $\mathrm{~ns}$ \\
\hline & & $\Delta T_{\text {canopy-air }}$ & ns & ns & ns & ns \\
\hline & & CWSI & ns & ns & ns & ns \\
\hline \multirow{6}{*}{$12: 30$} & \multirow{3}{*}{ Down } & $T_{\mathrm{C}}$ & $-0.57^{* *}$ & $-0.68^{* *}$ & $-0.65^{\star *}$ & $-0.46^{*}$ \\
\hline & & $\Delta T_{\text {canopy-air }}$ & $-0.78^{* *}$ & $-0.81^{* *}$ & $-0.80^{* *}$ & $-0.78^{* *}$ \\
\hline & & CWSI & $-0.74^{* *}$ & $-0.83^{* *}$ & $-0.80^{* *}$ & $-0.70^{* *}$ \\
\hline & \multirow{3}{*}{ Up } & $T_{\mathrm{C}}$ & $-0.57^{\star *}$ & $-0.70^{* *}$ & $-0.65^{\star \star}$ & $-0.48^{*}$ \\
\hline & & $\Delta T_{\text {canopy-air }}$ & $-0.83^{* *}$ & $-0.83^{* *}$ & $-0.78^{* *}$ & $-0.81^{* *}$ \\
\hline & & CWSI & $-0.71^{* *}$ & $-0.80^{* *}$ & $-0.77^{\star *}$ & $-0.70^{* *}$ \\
\hline
\end{tabular}

$\psi_{\text {st, }}$ stem-water potential;; $A_{N}$, net-photosynthesis; $g_{\mathrm{s}}$, stomatal conductance to water vapour; $E$,

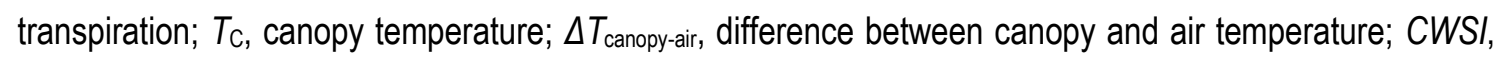
crop-water stress index. ns, no significant relationships; ${ }^{*}$ and ${ }^{* *}$ evidence significant correlations at 95 and $99 \%$, respectively. 
Table 3. Pearson's correlation coefficients between thermal indicators obtained at the two sampling times and sampled canopy location; and the volumetric soil-water content $\left(\theta, \mathrm{m}^{3} \mathrm{~m}^{-3}\right)$ measured at different depths $(10,20,30$ and $40 \mathrm{~cm}$, respectively).

\begin{tabular}{|c|c|c|c|c|c|c|}
\hline GMT & location & Thermal Indicator & $\theta_{10}$ & $\theta_{20}$ & $\theta_{30}$ & $\theta_{40}$ \\
\hline \multirow{6}{*}{ 10:30 } & \multirow{3}{*}{ Down } & $T_{C}$ & $-0.58^{* *}$ & $-0.66^{\star *}$ & $-0.52^{*}$ & $-0.48^{*}$ \\
\hline & & $\Delta T_{\text {canopy-air }}$ & ns & ns & ns & ns \\
\hline & & CWSI & $-0.44^{*}$ & $-0.57^{*}$ & $-0.54^{*}$ & $-0.46^{*}$ \\
\hline & \multirow{3}{*}{ Up } & $T_{\mathrm{C}}$ & $-0.43^{*}$ & $-0.49^{*}$ & ns & ns \\
\hline & & $\Delta T_{\text {canopy-air }}$ & ns & ns & ns & ns \\
\hline & & CWSI & ns & ns & ns & ns \\
\hline \multirow{6}{*}{$12: 30$} & \multirow{3}{*}{ Down } & $T_{\mathrm{C}}$ & $-0.76^{\star *}$ & $-0.57^{* *}$ & $-0.42^{*}$ & $-0.39^{*}$ \\
\hline & & $\Delta T_{\text {canopy-air }}$ & $-0.82^{* *}$ & $-0.76^{* *}$ & $-0.65^{\star *}$ & $-0.59^{* *}$ \\
\hline & & CWSI & $-0.79^{* *}$ & $-0.72^{* *}$ & $-0.60^{* *}$ & $-0.56^{*}$ \\
\hline & \multirow{3}{*}{ Up } & $T_{\mathrm{C}}$ & $-0.58^{\star \star}$ & $-0.69^{\star \star}$ & $-0.46^{*}$ & $-0.48^{*}$ \\
\hline & & $\Delta T_{\text {canopy-air }}$ & $-0.58^{\star *}$ & $-0.60^{* *}$ & $-0.55^{\star}$ & $-0.61^{* *}$ \\
\hline & & CWSI & $-0.69^{* *}$ & $-0.70^{* *}$ & $-0.62^{* *}$ & $-0.66^{* *}$ \\
\hline
\end{tabular}

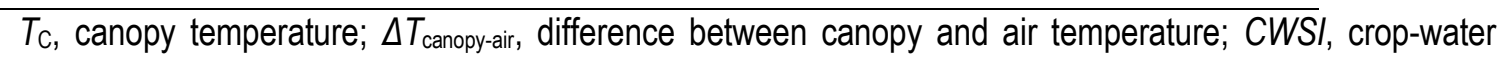
stress index; $\theta_{10}, \theta_{20}, \theta_{30}, \theta_{40}$, volumetric soil-water content at $10,20,30$ and $40 \mathrm{~cm}$ depth respectively; ns, no significant relationships; * and ${ }^{* *}$ evidence significant correlations at 95 and $99 \%$, respectively. 
Click here to download high resolution image

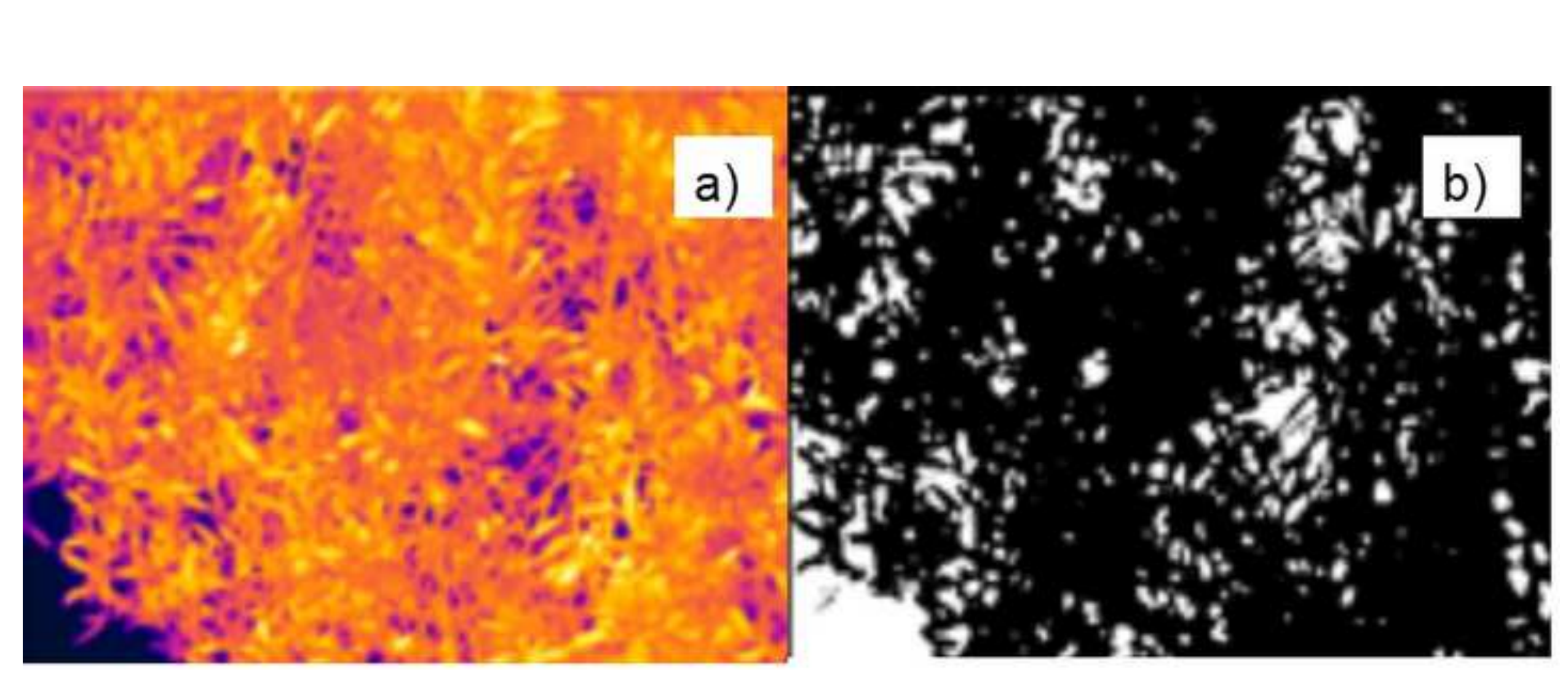




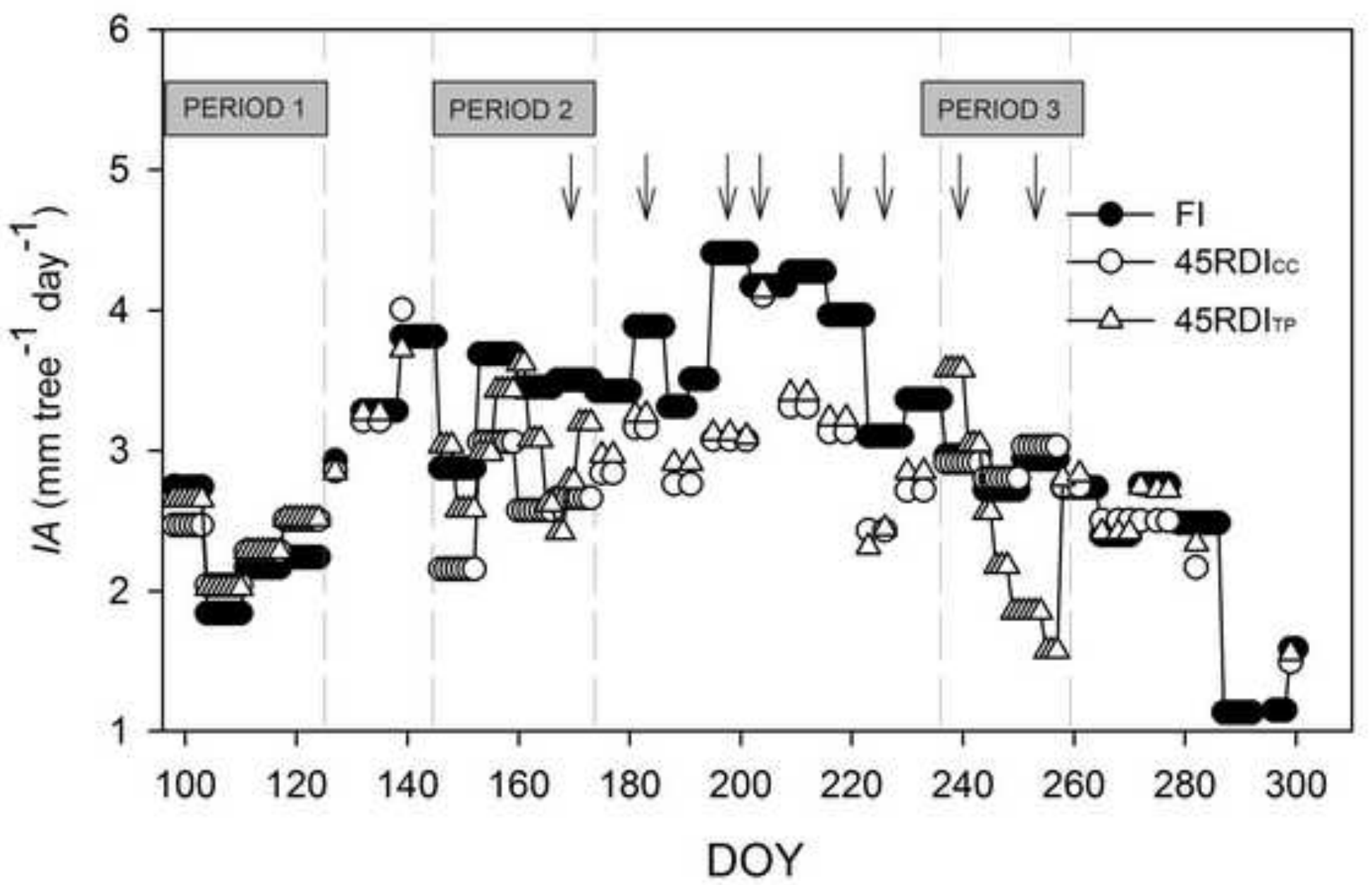



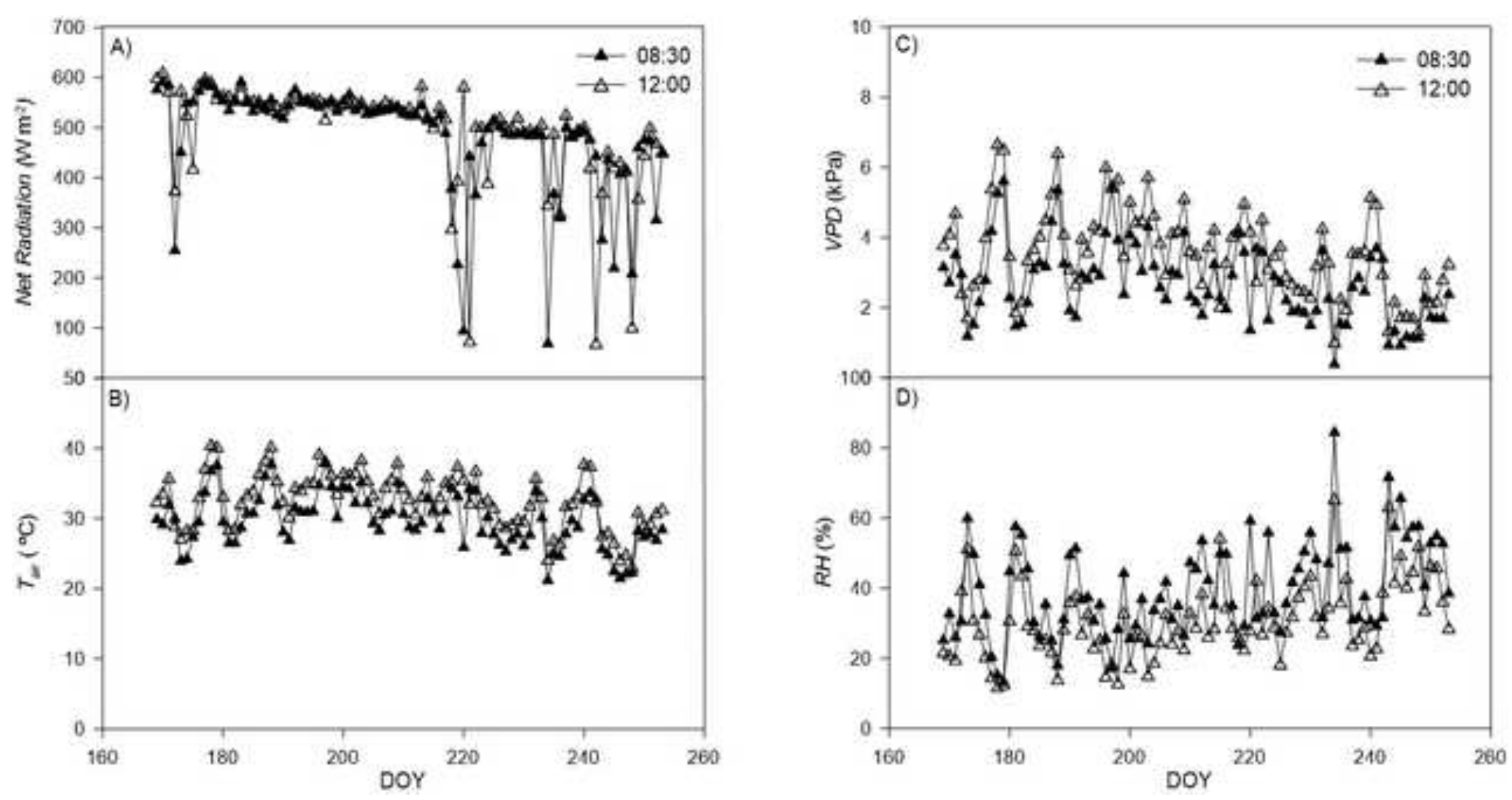

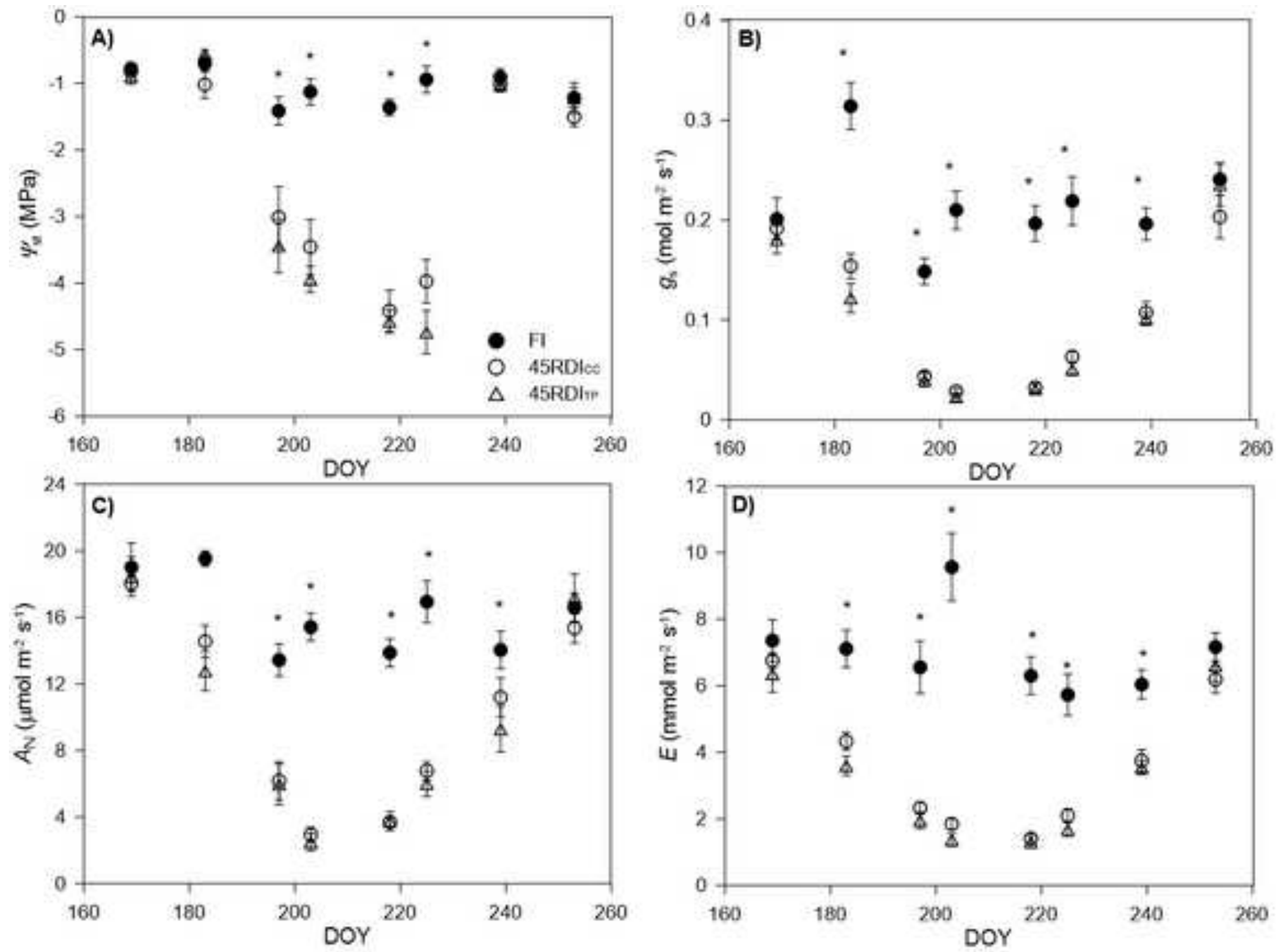

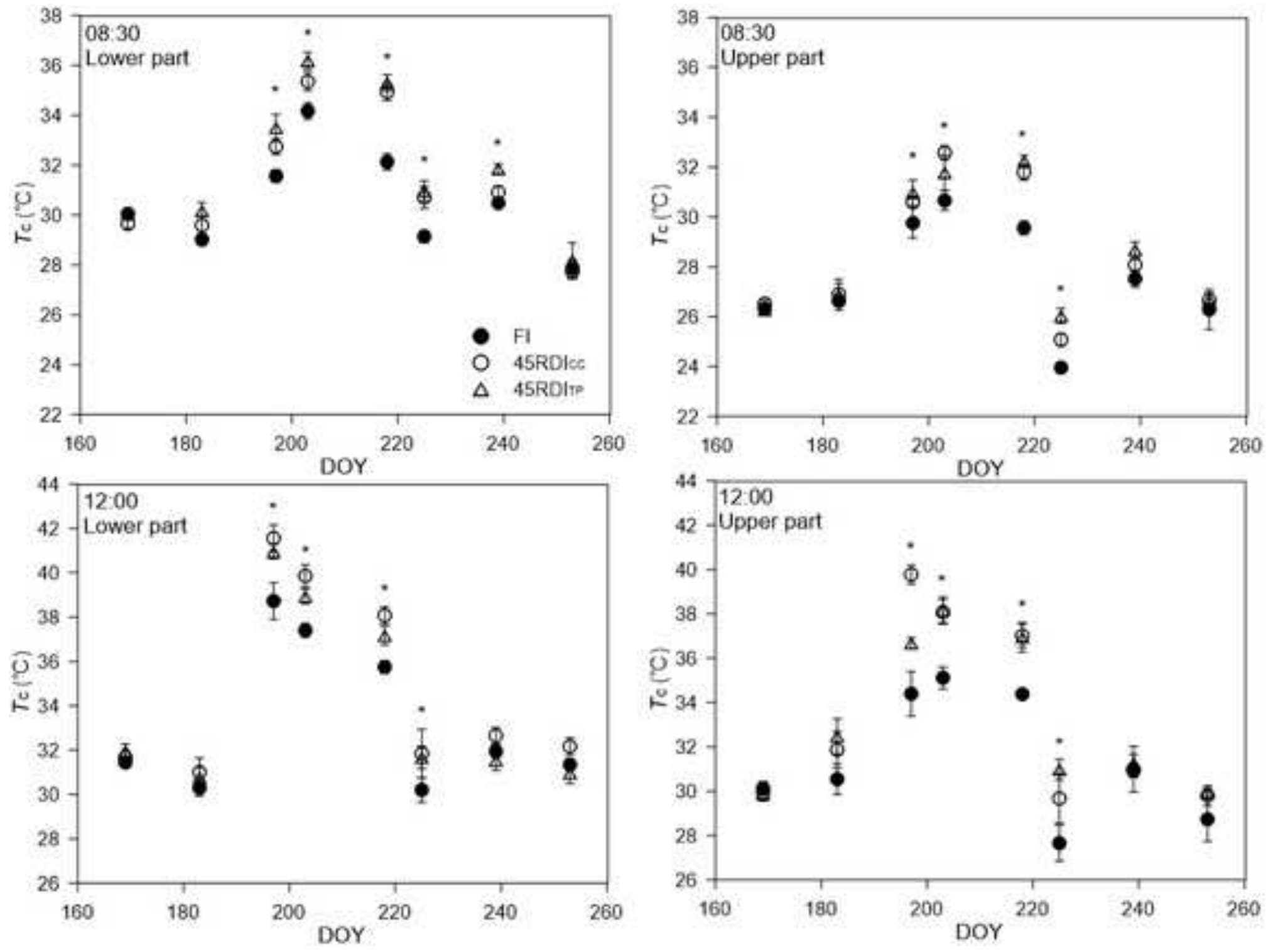

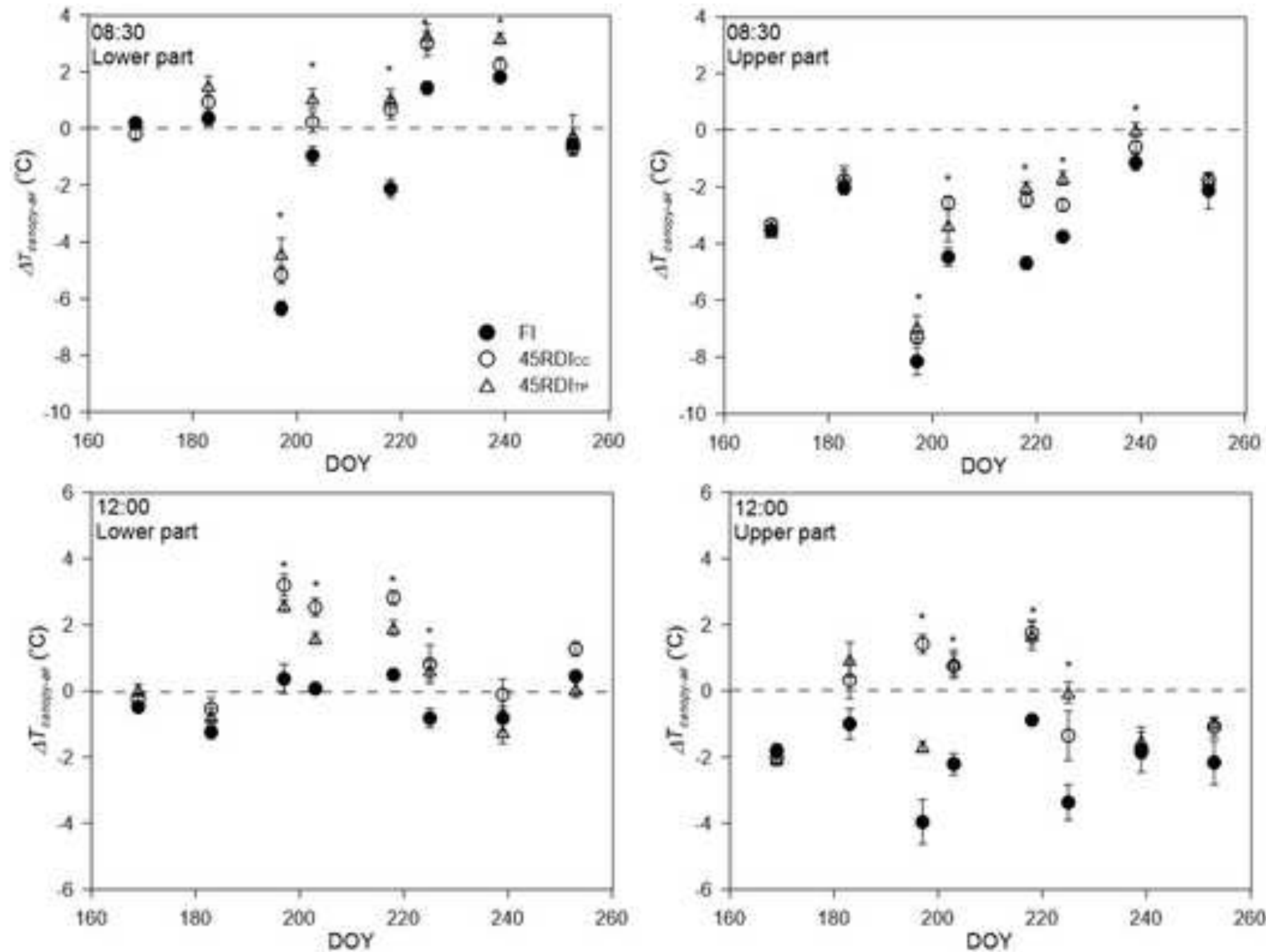

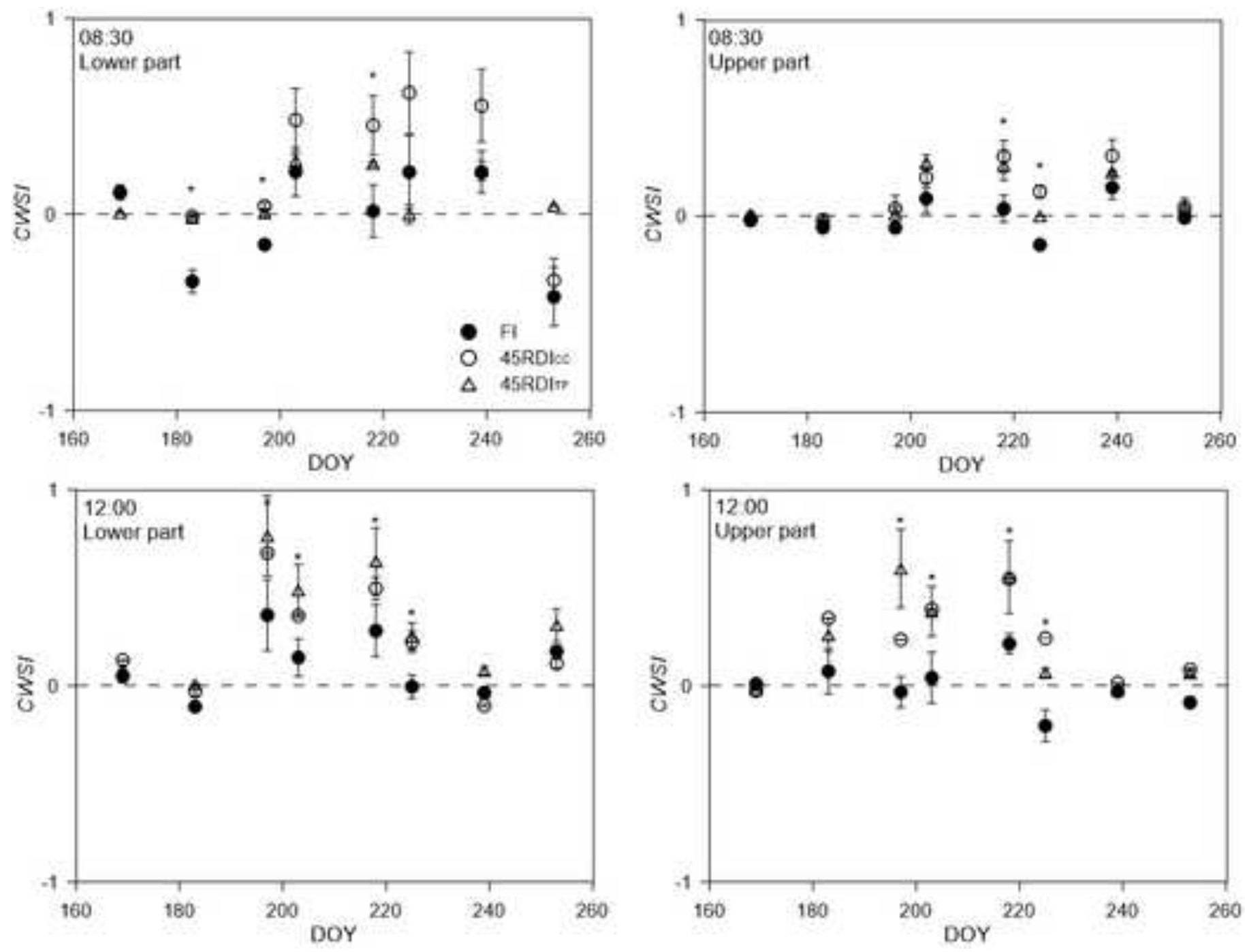

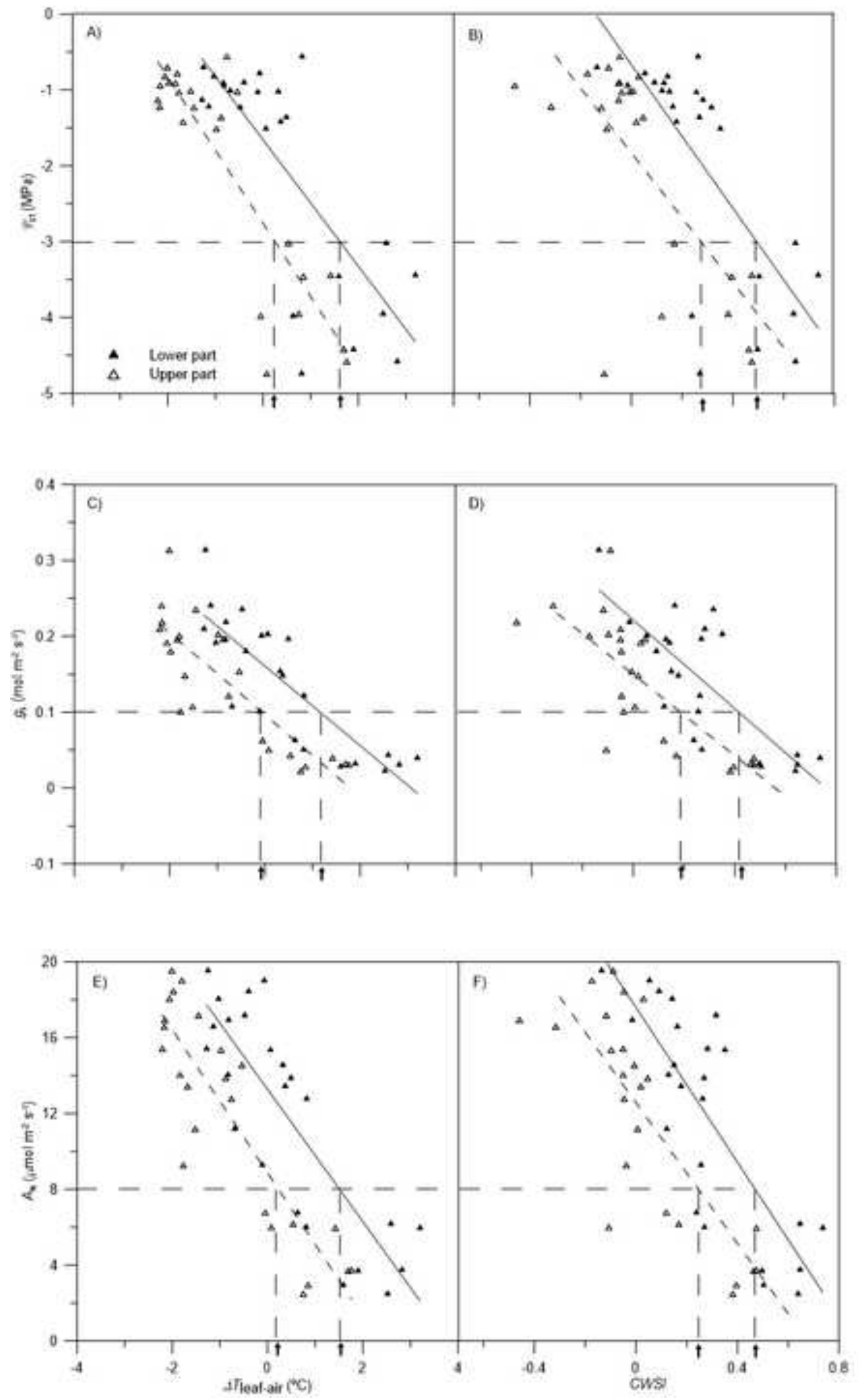


\title{
Assessing plant water status in a hedgerow olive orchard from thermography at plant level
}

\author{
García-Tejero, I.F., Hernández¹, A., Padilla-Díaz², C.M., Díaz-Espejo², A., Fernández², J.E. \\ ${ }^{1}$ Centro IFAPA "Las Torres-Tomejil". Ctra. Sevilla-Cazalla Km. 12.2 41,200. Alcalá del Río (Sevilla) \\ 2Irrigation and Crop Ecophysiology Group, Instituto de Recursos Naturales y Agrobiología de Sevilla \\ (IRNAS, CSIC), Avenida de Reina Mercedes, n. ${ }^{0}$ 10, 41012 Seville, Spain. \\ The authors belong to the Unidad Asociada "Gestión sostenible de los recursos suelo y agua". \\ e-mail corresponding author: ivanf.garcia@juntadeandalucia.es
}

\section{Abstract}

Water scarcity is the most limiting factor in many irrigated areas of Mediterranean countries such as South Spain. Olive growing has been traditionally associated to rain-fed agriculture, although irrigation and practices related to intensive agriculture have been progressively introduced, requiring a more precise irrigation scheduling to save water. Thermal imaging is among the alternatives to assess the crop water status, especially when deficit irrigation (DI) strategies are applied. However, this technique requires of new advances to be more user friendly and robust for practical usage. The aims of this study were: i) to define threshold values of canopy temperature $\left(T_{C}\right)$, Crop Water Stress Index (CWSI) and the temperature difference between canopy and the surrounding air ( $\left.\Delta T_{\text {canopy-air }}\right)$ for the assessment of the olive water status when a DI strategy is applied; ii) to define the best time of the day and the best area of the canopy to carry out thermal measurements, and iii) to obtain relationships between thermal indicators and main physiological parameters useful to estimate the crop water status from thermal data. The trial was conducted during 2015, in a hedgerow olive orchard (SW Spain) with 8-year-old trees (Olea europaea L., cv. Arbequina), under three irrigation regimes: a full-irrigation treatment (FI) and two regulated deficit irrigation treatments aimed to supplying $45 \%$ of the irrigation needs. In one of them, irrigation was scheduled from leaf turgor pressure related measurements $\left(45 R D I_{T P}\right)$. In the other, the crop coefficient approach was used to schedule irrigation (45RDIcc). Significant correlations between $T c$ versus stem water potential $\left(\psi_{\text {st }}\right)$ and leaf gas-exchange parameters (stomatal conductance to water vapor, $g_{s}$; net $\mathrm{CO}_{2}$ assimilation, $A_{N}$; transpiration, $E$ ) were obtained ( $\left.\mathrm{p} \leq 0.05\right)$, in particular from measurements taken at 10:30 GMT in the lower part of the sunlit side of the canopy. Moreover, the relationships between both $\Delta T_{\text {canopy-air }}$ and CWSI with the monitored physiological variables were very robust. We concluded that values of $\Delta T_{\text {canopy-air }}$ higher than $0{ }^{\circ} \mathrm{C}$ and values of $C W S I$ up to 0.2 reliably reflect the plant water stress. Our results, therefore, suggest that both $\Delta T_{\text {canopy-air }}$ and CWSI measured at midday provide reliable information on the tree water status and are useful to schedule irrigation in hedgerow olive orchards, especially under DI conditions. 
41 Keywords: Thermography, thermal indexes, water stress, irrigation scheduling, leaf-gas exchange 42 parameters, water potential.

43

44

\section{1.- Introduction}

Olive represents the most important tree crop in the worldwide in terms of surface, with a global area close to $11 \times 10^{6}$ ha. Most of the growing areas are located in Mediterranean European countries, being Spain the most relevant in terms of production, with over $2.5 \times 10^{6}$ ha devoted to this crop, from which ca. 400.000 ha are under irrigation (MAGRAMA 2016).

The number of olive orchards has significantly increased in the last few years and, in many countries, hedgerow olive orchards with high plant densities (over 1500 trees ha-1), also called super-high-density (SHD) orchards, are becoming popular. This type of orchard covers a surface of ca. 100,000 ha (Rius and Lacarte, 2015). According to forecast predictions (IPCC, 2014), water can be the most limiting factor for olive growing, particularly for irrigated SHD orchards (Vossen et al., 2004). Therefore, effective water management is crucial to increase the productivity of this natural resource, especially in areas such as South Spain, where climatic conditions are characterized by rainfall scarcity and a highly irregular spatial and temporal distribution of the rainfall events (Garcia-Tejero et al., 2013).

Deficit irrigation (DI) strategies are highly effective for both improving water productivity and achieving a sustainable agricultural development. A properly chosen DI strategy saves water without highly affecting yield, and it has usually with a positive impact on quality (Fereres and Soriano, 2007; Geerts and Raes, 2009; Ruiz-Sánchez et al., 2010). Moreover, DI limits excessive growth, which is important in SHD orchards, where tree size has to be controlled for both optimum illumination and mechanical harvesting (Cuevas et al., 2013). In this line, authors such as Fernández et al. (2013), Gómez del Campo (2013) and Padilla-Díaz et al. (2016) have demonstrated that regulated deficit irrigation (RDI) can be a suitable strategy to improve irrigation water management and water productivity in SHD olive orchards. RDI strategies are based on avoiding excessive water stress in the periods of the growing cycle when the crop is highly sensitive to drought, so the effective monitoring of plant water status along the crop growing cycle becomes crucial (Poblete-Echeverría et al., 2014; Fernández 2014a).

There is a substantial amount of literature on the usefulness of different methods for the continuous monitoring of crop water status, such as those based on the use of dendrometers (Moriana et al., 2010 or Cuevas et al., 2010), sap-flow (Fernández et al., 2008a; Fernández, 2014a) or leaf turgor pressure probes (Zimmerman et al., 2008; Fernández et al., 2011a). Studies on their applicability to commercial orchards proved that additional information on crop-water status is often required to properly evaluate the information collected by those sensors (Fernández, 2014b). Thus, leaf or stem water potential and gas-exchange related measurements, apart of being used alone to monitor the plant water status, are often combined with the methods mentioned above. These water stress indicators have also their limitations. According to Martín-Vertedor (2011) and Fernández (2014a,b), leaf or stem water potential 
measurements are good indicators of olive water status, but they are not suitable for precision agriculture because they cannot be automated. In fact, their use is based on destructive, noncontinuous, high labour- and time-consuming measurements. Something similar occurs with gasexchange measurements, such that they are more widely used with research purposes than in commercial orchards (Poblete Echeverría et al., 2016).

New irrigation approaches, such as precise irrigation, are technically demanding. This is behind the increasing interest in the use of remote sensing to monitor crop water status at different scales (at plant or orchard level). In this sense, thermal imaging emerged as a non-invasive approach to assess the crop-water status and to schedule irrigation, as probed from findings in citrus trees (García-Tejero et al., 2011; González-Dugo et al., 2014); almonds (García-Tejero et al., 2012), vines (Costa et al., 2012; García-Tejero et al., 2016) and olives (Berni et al., 2009; Poblete-Echeverría et al., 2014, 2016), among other crops. The principle of thermography relies on the leaf energy balance. Water stress induces stomatal closure, which in turn limits leaf transpiration, and hence the evaporative cooling process. This results in higher leaf/canopy temperature values (Jones, 1999, 2004). Thermal readings provide reliable information on the crop physiological status. Still, relationships between thermal information and main physiological parameters such as the stomatal conductance to water vapour $\left(g_{\mathrm{s}}\right)$, net $\mathrm{CO}_{2}$ assimilation $\left(A_{N}\right)$, transpiration $(E)$, or the crop water status (in the basis on the leaf or stem water potential) are usually required to properly evaluate the information provided by thermal readings (Jones 2004; Jones et al., 2009). These relationships, however, depend on weather variables as $T_{\text {air, }}$ incident radiation, the angle of incident radiation, wind speed and vapour pressure deficit (Jones, 1999; 2004). They also depend on monitoring proceedings (González-Dugo et al., 2012; Costa el al., 2013), cultivars (Costa et al., 2012; García-Tejero et al., 2016) and developmental stage (Cohen et al., 2015), among other factors. This has led to the testing of different strategies to optimize thermography, which included the development of effective protocols for field measurements based on thermal indices (Jones et al., 2002; 2009; Grant et al., 2006; Möller et al., 2007; Baluja et al., 2012; Bellvert et al., 2014) and robust relationships between thermal information and physiological parameters. However, some questions are still under debate, e.g. which is the most practical, although robust, thermal index that can be a proxy of plant physiological traits (e.g. leaf gas-exchange behavior). Another matter of debate is whether the thermal measurements could be directly used, without any additional relationship with other physiological variables, and whether threshold values, similar to those defined for stem or leaf water potential, or stomatal conductance, can be established.

We hypothesize that thermography could be a suitable approach to assess the crop water status in a SHD olive orchard. To test our hypothesis, we carried this work in a representative, fully productive SHD olive orchard with the aims of: (i) to derive threshold values for the plant water status from thermal related data collected in the orchard (canopy temperature, $T_{\mathrm{C}}$; the temperature difference between

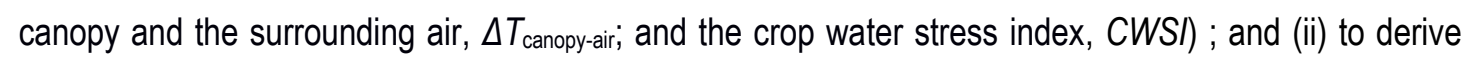
relationships between thermal readings and main physiological variables (stem water potential, $\Psi_{\text {sti; }}$ 
115 stomatal conductance to water vapor, $g_{s}$; net $\mathrm{CO}_{2}$ assimilation, $A_{N}$, and transpiration, $E$ ). We explored

116 the suitability of taking the thermal readings at different moments of the day and in different locations of

117 the canopies.

\section{2.- Material and Methods}

120 2.1.- Experimental Site

121 The trial was conducted during the irrigation season of 2015 , in a super-high-density olive (Olea

122 europaea L., cv. Arbequina) orchard located at $25 \mathrm{~km}$ of Seville $\left(37^{\circ} 15^{\prime} \mathrm{N}, 5^{\circ} 48^{\prime} \mathrm{W}\right)$. The trees were 123 planted in 2007 at the top of $0.4 \mathrm{~m}$ high ridges and spaced $4 \mathrm{~m} \times 1.5 \mathrm{~m}$ (1667 trees ha-1), with the rows 124 oriented N-NE to S-SW.

125 The orchard soil is an Arenic Albaqualf (USDA, 2010) with a sandy loam top layer (77.7\% sand, $20.1 \%$

126 clay and $2.2 \%$ silt) of $1.73 \mathrm{Mg} \mathrm{m}^{-3}$ bulk density $(\rho)$ and soil hydraulic conductivity near saturation ( $\left.\mathrm{K}_{\text {sat }}\right)$ 127 of $40.7 \mathrm{~cm}$ day $^{-1}$. Downwards there was a sandy clay layer $(60.9 \%$ sand, $37.1 \%$ clay and $2.0 \%$ silt) 128 with $\rho=1.82 \mathrm{Mg} \mathrm{m}^{-3}$ and $\mathrm{K}_{\mathrm{sal}}=3.54 \mathrm{~cm}$ day $^{-1}$. The average depth from the top of the ridges to the clayey 129 soil layer was $0.6 \mathrm{~m}$. The clay layer was not reached by the roots, since the maximum depth of the root 130 system was $0.45 \mathrm{~m}$ (Diaz-Espejo et al., 2012).

131 Trees were irrigated with an automatic controller (Agronic 2000, Sistemes Electrònics PROGRÉS, S.A., 132 Lérida, Spain) and a pipe line per row, with three $2 \mathrm{~L} \mathrm{~h}^{-1}$ drippers per tree, spaced $0.5 \mathrm{~m}$. Fertilizers 133 were injected into the irrigation system once a week during the irrigation period, receiving all trees the 134 same amount of nutrients, enough to cover the crop needs (Fernández et al., 2013).

135 The climate of the experimental area is Mediterranean, with mild winters and hot dry summers. Most 136 rainfall events in the area occurs between September and May, the summers being dry and hot. The 137 average values of precipitation and potential evapotranspiration are $537.3 \mathrm{~mm}$ and $1504.0 \mathrm{~mm}$, 138 respectively (2010-2015 period). During the hottest months (July and August) the maximum values of 139 air temperature can easily go over $40^{\circ} \mathrm{C}$, whereas in the coolest months (December and January) air 140 temperature rarely drops below $-5^{\circ} \mathrm{C}$.

\section{2.2.- Experimental design and irrigation treatments}

143 The experimental design was a randomized complete block with four replicates per treatment. The 144 experimental unit $\left(192 \mathrm{~m}^{2}\right)$ had four rows with eight trees per row, being the eight central trees (four 145 trees for the two central rows) considered as sampling trees, surrounded by 24 border trees. Three 146 irrigation treatments were defined: (i) A full irrigation $(\mathrm{FI})$ treatment, in which the trees were daily 147 irrigated to replace $100 \%$ of the irrigation needs (IN). The latter were calculated as the difference 148 between crop evapotranspiration $\left(E T_{c}\right)$ and effective precipitation $\left(P_{e}\right) . E T_{c}$ was calculated with the crop 149 coefficient approach (Allen et al., 1998; see Fernández et al., 2013, for details). (ii) A regulated deficit 150 irrigation treatment (45RDIcc) aimed to replace 45\% of IN (see Padilla-Díaz et al., 2016, for details). 151 Basically, daily irrigation amounts (IA) similar to IN were applied in the three periods of the growing 
152 cycle when the crop is most sensitive to water stress, defined as Period 1 (around bloom, in April)

153 Period 2 (during the maximum rate of pit hardening, in June) and Period 3 (during the stage of fast oil

154 accumulation, from the end of August to mid-September) (Fernández, 2014a). Between Periods 1 and 2

155 an irrigation event per week was applied when the soil water content was below $70 \%$ of the maximum

156 soil water holding capacity. Between Periods 2 and 3, two irrigation events per week were applied (iii) a 157 second 45RDI treatment similar to the already described, but in which irrigation was scheduled from leaf turgor pressure readings (45RDITP) (see Padilla-Díaz et al., 2016, for details).

\section{3.- Soil and plant measurements}

161 The effect of the irrigation treatments on main physiological variables, including canopy temperature, 162 was established from measurements in June 18th (day of year -DOY- 169), July $2^{\text {nd }}, 16^{\text {th }}$ and $22^{\text {th }}$ (DOY 163183,197 and 203), August $6^{\text {th }}, 13^{\text {th }}$ and $27^{\text {th }}$ (DOY 218, 225 and 239), and September 10th (DOY 253). 164 Measurements of stem water potential at midday $\left(\psi_{\mathrm{st}}\right)$ were made with a Scholander-type pressure chamber (PMS Instrument Company, Albany, Oregon, USA). One leaf per tree close to a main branch was sampled, from two representative trees per plot $(n=8)$, at around 12:00 GTM, the time for minimum $\psi_{\text {st }}$ in olive. The chosen leaves were wrapped in aluminum foil ca. $2 \mathrm{~h}$ before sampling.

168 Measurements of stomatal conductance to water vapor $\left(g_{\mathrm{s}}\right)$, net $\mathrm{CO}_{2}$ assimilation $\left(A_{N}\right)$ and transpiration 169 (E) were made with a portable infrared gas analyzer (LI-6400; LiCor Inc., Lincoln, Nebraska, USA), with 170 a $6 \mathrm{~cm}^{2}$ transparent leaf chamber and the air-flow rate set at $350 \mu \mathrm{mol} \mathrm{s}^{-1}$. Measurements were taken in 171 one fully expanded and sunlit leaf per tested tree, using 8 trees per irrigation treatment $(n=8)$. 172 Measurements were made around 08:30 GMT, the time for maximum $g_{\mathrm{s}}$ in olive.

173 Canopy temperature $(T c)$ was derived from thermal images were made on the same days that the 174 mentioned physiological measurements, both at 08:30 and 12:00 GTM, and both at the bottom $(1.5 \mathrm{~m}$ 175 from the soil surface) and the top ( $2.5 \mathrm{~m}$ from the soil surface) of the sunlit side of eight trees per 176 treatment $(n=8)$. These regions were previously defined, and the canopy surface taken in each image 177 corresponded with a single tree (the first one for the down area of the canopy, and the second one for 178 the upper area of the canopy). We use a ThermaCam (Flir SC660, Flir Systems, USA, 7-13 $\mu \mathrm{m}$, $179640 \times 480$ pixels). Each pixel corresponded to an effective temperature reading and the emissivity $(\varepsilon)$ was 180 set at 0.96 . The background temperature was determined by measuring the temperature of a crumpled 181 sheet of aluminum foil placed near the sampled leaves using $\varepsilon=1$ (Jones et al., 2002). The imager was placed perpendicularly to the canopy, at about $2 \mathrm{~m}$ from the sunlit side. For the images taken in the

183 down part, a cooled white screen was used as background, that being placed behind of each monitored 184 tree to simplify the isolation of the canopy surface through image processing. For the images of the 185 upper part, the regions of sky were used as the background. Thermal images were analysed with the 186 software developed by García-Tejero et al. (2012). This software allows to work with up to three 187 sections for each analyzed image, to select the temperature range corresponding to pixels of the 
188 canopy, and to remove those areas or pixels that do not have to be considered, i.e. those corresponding 189 to the stem and the background (Figure. 1).

190 In order to normalize the thermal information and taking the absolute values of $T_{\mathrm{C}}$ as the starting point,

191 two thermal indexes were estimated: the difference between canopy and the surrounding air ( $\Delta T_{\text {canopy-air }}$ )

192 and the crop water stress index (CWSI); these being calculated as follows (Idso, 1981; Jackson et al., 193 1981):

$195 \Delta T_{\text {canopy-air }}=T_{\mathrm{C}}-T_{\text {air }}$

$197 \quad C W S I=\frac{\Delta T-\Delta T w e t}{\Delta T d r y-\Delta T w e t}$

where $\Delta T_{\text {canopy-air, }} \Delta T_{\text {dry }}$ and $\Delta T_{\text {wet }}$ is the difference between canopy and air temperature in the moment 200 of the measurement, $T_{\mathrm{C}}$ is the temperature of the canopy, $T_{\text {air }}$ is the temperature of the surrounding air, 201 and $\Delta T_{\text {dry }}$ and $\Delta T_{\text {wet }}$ are the difference between canopy and air temperature when the crop has the 202 stomata fully closed and when is fully transpiring, respectively.

204 To obtain the reference values of $\Delta T_{\text {wet }}$ we calculated the non-water stress baselines $\left(\Delta T_{\text {canopy-air }}=\mathrm{a}+\right.$ $205 b^{*} V P D$ ) according to Idso et al. (1981), and used a $\Delta T_{\text {dry }}$ value equal to $5^{\circ} \mathrm{C}$, as proposed by Jackson et 206 al. (1982). Non-water stress baselines were defined for two different moments of the day (08:30 and 207 12:00 GTM, respectively), i.e. when $T_{\mathrm{C}}$ readings were made. Moreover, as $T_{\mathrm{C}}$ readings were obtained 208 from two different areas of the tree (down and topside), these functions were defined for each location. 209 Thus, four relationships between VPD vs. $\Delta T_{\text {canopy-air }}$ were estimated for each monitoring time (08:30 and 210 12:00 GTM) and parts of the canopy (at the bottom and top). In all cases, these relationships were 211 derived from the canopy temperature readings in FI trees.

212 Finally, soil water content was measured by using a Profile probe (Delta-T Devices Ltd., Cambridge,

213 UK), recording the volumetric soil water content $(\theta)$ values in the root zones of three trees per treatment.

214 Each access tube was installed at $0.5 \mathrm{~m}$ from the tree trunk, measuring the soil-water content at 10, 20,

21530 , and $40 \mathrm{~cm}$, coinciding the measurement days with those days in which the physiological 216 measurements were done. Previously, the Profile probe was calibrated in situ as it was described by 217 Fernández et al. (2011b).

219 2.4.- Statistical analysis

220 For each measurement day, an exploratory and descriptive analysis of physiological measurements and 221 canopy readings was made after applying a Levene's test to check the variance homogeneity of the 222 studied variables. Significant differences between irrigation treatments $(p \leq 0.05$ and $p \leq 0.01)$ in the 
223 studied variables were identified by applying a one way ANOVA and a Tukey's test for treatment 224 separation, with the SPSS statistical software (SPSS Inc., 15.0 Statistical package; Chicago, IL, USA).

225 To evaluate the non-water stress baselines for each sampling time and canopy location, a linear 226 correlation analysis was made $(n=8)$ with a covariance analysis at a confidence level of $95 \%$. That 227 allowed to compare the functions (slope and intercept) and evaluate significant differences.

228 To evaluate the relationships between variables, a linear correlation analysis between the thermal 229 indicators ( $T_{\mathrm{C}}, \Delta T_{\text {canopy-air }}$ and $\left.C W S I\right)$ and the physiological variables $\left(\psi_{\mathrm{st}}, \mathrm{g}_{\mathrm{s}}, A_{\mathrm{N}}\right.$ and $\left.E\right)$ and $\theta$ at the 230 different depths was made for each sampling time and location $(n=24)$. The obtained correlation 231 coefficients were used to identify both the best time and location to carry out $T_{\mathrm{C}}$ readings. This allowed 232 us to assess the reliability of the mentioned thermal indicators as a proxy for crop physiology traits.

233 Once selected the best moment of the day to carry out the $T_{\mathrm{C}}$ readings, and the most representative 234 thermal indicator, the obtained linear regressions for each sampling location in the canopy were 235 compared (slope and intercept) using a covariance analysis at a confidence level of $95 \%$.

\section{3.- Results and discussion}

\subsection{Meteorological conditions, irrigation events and physiological measurements}

Figure 2 shows the irrigation events applied in each irrigation treatment. According to the chosen

243146 to 173 ) and Period 3 (DOY 237 to 257 ) all the trees were daily irrigated to replace crop 244 requirements. In Period 2 the $\mathrm{FI}$ trees received $102 \%$ of irrigation needs (IN), whereas $45 \mathrm{RDI}$ TP and $24545 \mathrm{RDI}_{\mathrm{cC}}$ trees received $90 \%$ and $79 \%$ of IN, respectively. In between Periods 2 and 3 (DOY 174 to

246 236), FI trees received $107 \%$ of IN, whereas both $45 R D I_{\text {TP }}$ and $45 R D I_{\text {cc }}$ received $24 \%$ and $25 \%$ IN 247 respectively, with two or three irrigation events per week. Finally, during Period 3 all trees were daily 248 irrigated again, receiving $106 \%$ of $\mathrm{IN}$ the $\mathrm{FI}$ trees $89 \%$ the $45 \mathrm{RDI} \mathrm{I}_{\mathrm{TP}}$ trees and $107 \%$ the $45 \mathrm{RDI} \mathrm{I}_{\mathrm{CC}}$ trees.

249 Seasonal courses of main weather variables recorded at the two sampling times of the day are shown in

250 Figure. 3. The highest values of temperature and net radiation were recorded at the beginning of the 251 experimental period (June), while top values of relative humidity were recorded at the end (September).

252 Values of vapor pressure deficit were quite high all along the experimental period, especially at the 253 beginning.

254 The seasonal courses of $\psi_{\text {st }}$ and gas exchange measurements were in line with the irrigation strategies 255 applied in each treatment (Figure 4). At the beginning of the experimental period (DOY 169) no 256 differences between treatments were found for any physiological variable. This is in agreement with the 257 fact that during Period 2 all trees received irrigation amounts close to the irrigation needs (Figure 2).

258 At the beginning of the stress-increasing period (DOY 183, nine days after the end of Period 2) we 259 found a faster decrease in gas exchange than in $\psi_{\text {st. }}$ A similar behaviour was observed by Torres-Ruiz 260 etal. (2013) and Pérez-Martín et al. (2014) in 'Manzanilla' olive trees. They related this behaviour with 
261 the effective stomata control of plant water status in this species, mainly in the first stages of water 262 stress (Fernández et al., 1997; Fernández 2014a). Later, from DOY 183 to 225, stomatal conductance

$263\left(g_{\mathrm{s}}\right)$, net $\mathrm{CO}_{2}$ assimilation $\left(A_{N}\right)$ and consequently leaf transpiration $(E)$, decreased progressively in the

$264 \mathrm{RDI}$ trees. This is in accordance with those trees were receiving just ca. $25 \%$ of IN in that Period. The 265 lowest values of these three variables were recorded on DOY 218.

266 Later in the season, and in agreement with the greater water supplies of Period $3, g_{s}, A_{N}$ and $E$ values in $267 \mathrm{RDI}$ trees became similar to those recorded in $\mathrm{FI}$ trees, showing a full recovery of the trees on that 268 period. However, at the beginning of this period, values of $\psi_{\text {st }}$ recovered quicker than those of gas 269 exchange related variables. This is also typical in olive (Fernández, 2013, Perez-Martin et al., 2014).

270 The $\mathrm{Fl}$ trees showed values of $\psi_{\mathrm{st}}, g_{\mathrm{s}}, A_{\mathrm{N}}$ and $E$ close to the maximum for olive trees under non-limiting 271 conditions (Diaz-Espejo et al., 2006), all along the experimental period.

272 Significant differences in $\psi_{\text {st }}$ among treatments were observed in between Periods 2 and 3 , when these 273 values were progressively descending in $45 \mathrm{RDI}$ trees till reaching a minimum value of $-4.4 \pm 0.1 \mathrm{MPa}$ 274 on DOY 218 and 225 . This descend was accompanied with a depletion in gas-exchange parameters, 275 being recorded the minimum values when $\psi_{\text {st }}$ was close to $-3 \mathrm{MPa}$. (Figure 4).

\subsection{Diurnal evolution of canopy temperature and related thermal indices}

278 Figure 5 shows the average of canopy temperature readings taken at the two sampling times and 279 locations, for the three irrigation treatments during the monitoring period. For all treatments and 280 sampling times, differences were observed between the down and the upper part. These differences 281 were especially remarkable at 08:30 GMT, when values in the upper part were up to $5^{\circ} \mathrm{C}$ below those 282 from the down part. This could be due to heat transmission from the soil to the down part of the canopy 283 or to greater heat dissipation in the upper part because of the wind. The first differences between $\mathrm{Fl}$ and 284 RDI trees appeared on DOY 197, these differences being more evident at 08:30 GMT on the down part, 285 whereas, at 12:00 GMT the differences were significant in both sampling areas. Differences in $T_{\mathrm{C}}$ 286 between treatments increased along the season, being greater at 12:00 than at 08:30 GMT, and in the 287 lower part of the canopy that at the upper part. Depending on the location and sampling time, 288 differences among treatments ranged from 2 to $6^{\circ} \mathrm{C}$.

289 Our results agree with those reported for other olive orchards of different locations and characteristics. 290 Sepulcré-Cantó et al. (2006) detected differences close to $2^{\circ} \mathrm{C}$ by using infrared sensors installed $1 \mathrm{~m}$ 291 above the olive crown. Poblete-Echeverría et al. (2016), in a study developed in 'Arbequina' trees, 292 registered temperature differences around $4-5^{\circ} \mathrm{C}$, at the moments of maximum stress level $\left(\psi_{\text {st }}<-5\right.$ 293 MPa). Other authors such as Testi et al. (2008) in Pistachio, García-Tejero et al. (2011) in citrus trees, 294 and García-Tejero (2016) in vines reported temperature differences of $2-6^{\circ} \mathrm{C}$ between fully irrigated and 295 stressed trees.

296 It is noticeable that differences between treatments in $T_{\mathrm{c}}$ were detected when the lowest $g_{\mathrm{s}}$ values were 297 recorded (DOY 197 to 225 DOY, Figures 4 and 5). Nevertheless, $T_{C}$ readings in Fl treatment showed a 
high variation, probably associated to differences in meteorological conditions during the sampling days.

299 As it has been previously stated, the effect of stomatal regulation (partial closure) under a mild or 300 moderate water stress is that leaf temperature trends to increase, because of a decrease in the heat 301 dissipated by transpiration (Jones et al., 2002; 2009; Jones and Vaughan, 2010). According to Jones et 302 al. (2009) and Jones and Vaughan (2010), there are many variables such as the radiation level, air 303 temperature, vapour pressure deficit, the relative humidity or the angle of the radiation incident on the 304 leaf surface that will influence decisively on the absolute value of $T_{\mathrm{c}}$. Therefore all of them must be 305 taken into account when making an assessment of crop water status from thermal information. This 306 explains the difficulty of establishing a threshold value of $T_{\mathrm{C}}$ for irrigation scheduling and crop-water 307 status monitoring. This is a limitation of the thermal approach as compared to $\psi_{\mathrm{st}}$ or $g_{\mathrm{s}}$, variables for 308 which threshold values for water stress can be more easily established (Fernández et al. 2008b; 309 Moriana et al., 2012).

310 Once normalized the $T_{c}$ readings by estimating the difference between canopy and the surrounding air 311 ( $\left.\Delta T_{\text {canopy-air }}\right)$, we observed $\Delta T_{\text {canopy-air }}$ values below $0^{\circ} \mathrm{C}$ for the $\mathrm{FI}$ trees, especially at 12:00 GMT, and 312 with a temporal variation much less than detected for $T_{\mathrm{C}}$ readings (Figure 6). This is in line with the 313 results reported by Sepulcré-Cantó (2006) and Poblete-Echeverría (2016), from readings taken in 314 similar conditions. This corroborates what we have stated above for the thermal readings at 12:00 GMT 315 and in the down part of the canopy, these being the most informative in terms of tree water status. Thus, 316 by comparing the $\Delta T_{\text {canopy-air }}$ values detected in $\mathrm{Fl}$ trees versus those in RDI trees, we defined a 317 threshold value of $\Delta T_{\text {canopy-air }}=0^{\circ} \mathrm{C}$, above which a severe water stress situation would be being 318 supported by the crop.

319 After using the methodology proposed by Idso et al. (1981) and Jackson et al. (1981) to derive non-

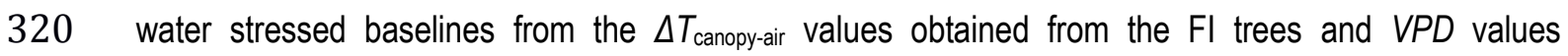
321 registered for each time and monitoring day, significant relationships were obtained for the four 322 sampling situations, especially for the measurements at 12:00 $\mathrm{h}$ (Table 1). For the readings taken at 323 12:00 GMT in the down part, the slope was similar to that obtained by other authors such as Berni et al. 324 (2009) in 'Arbequina' olive trees (-0.35) from measurements $1 \mathrm{~m}$ above the trees, although the intercept 325 point was different (2.08). According to these authors, the explanation of the low slopes derived from the 326 non-water stressed baselines would the small size of the olive leaves, which are very coupled to the 327 atmosphere (Villalobos et al., 2000) and because of the marked stomatal control even in full irrigated 328 trees, when the evaporative demand is very high. As a consequence of this slope, CWS/ estimation in 329 olive trees is very much affected by errors in both the estimation of $T \mathrm{c}$ and the measurement of $T_{\text {air }}$ 330 (Berni et al., 2009). More interesting were the reflections argued by these authors, when they compared 331 effect of net radiation and wind speed in the interception point, suggesting that the slopes obtained for 332 different non-water stressed baselines estimated from a theorist proposed model by them were very 333 similar to the obtained from empirical information; and the highest variations were observed in the 334 interception point. Similar results were reported Testi et al. (2008) in pistachio trees, evidencing that 
335 daily variations in net radiation resulted in parallel baselines, i.e. the slope of the baseline was not 336 affected.

337 Figure 7 shows the CWSI evolution calculated by using the non-water stressed baselines defined in

338 Table 1 according to the $T_{C}$ values of $F$. The seasonal course of this index was similar to that of $339 \Delta T_{\text {canopy-air }}$ (Figures 6 and 7). The greatest differences in CWSI between treatments were reached from 340 DOY198 to DOY 225, especially at 12:00 GTM. The lowest CWSI values were found in the FI trees, 341 being around 0 (dimensionless), especially during the readings taken at 12:00 and at 08:30 GTM in the 342 down part. However, CWSI values derived from the thermal readings at 12:00 GMT in both parts of the 343 canopy were occasionally higher than $0^{\circ} \mathrm{C}$ in the $\mathrm{FI}$ trees, which were under non-limiting soil water 344 conditions. This could be related to the sensitiveness of CWSI to weather conditions, e.g. solar radiation 345 (Agam et al., 2013), or to tree architecture (González-Dugo et al., 2014). In any case, this is a limitation 346 of CWSI that curtails its potential as a reliable index to schedule irrigation. Such limitation was not 347 detected for $\Delta T_{\text {canopy-air. }}$ The fact that threshold values for the assessment of the crop water status 348 cannot be easily derived from thermal readings is acknowledged as one of the main limitations of this 349 technique to schedule irrigation in commercial orchards.

\section{3.- Relationships between the thermal information, physiological variables and soil-water content}

352 In the last few years, many works have been developed to optimize the use of thermography to assess 353 the crop-water status and to schedule irrigation (Jones et al., 2002; Leinonen and Jones, 2004), 354 reporting significant correlations between thermal information and other related physiological variables 355 (Berni et al., 2009; Poblete-Echeverría et al., 2014; Osroosh et al., 2016). In our case, relationships 356 between thermal and physiological data were derived to define the most efficient thermal index and the 357 best sampling time to assess the crop water status. Table 2 shows the Pearson's correlation coefficients 358 obtained for the relationships corresponding to the measurements taken at 08:30 and 12:00 GMT in the 359 lower and upper part. Regarding $T_{C}$, the most significant correlations were obtained at 12:00 GTM, 360 these being very similar for both the readings in the down part and in the upper part. Moreover, a similar 361 robustness was observed for the relationships derived from the readings taken at 08:30 in the down 362 part. This did not apply to measurements from the upper part. Regarding the coefficients obtained for $363 \Delta T_{\text {canopy-air }}$ and $C W S I$ with the physiological parameters, these were better than those for $T c$, especially 364 for the readings taken at 12:00 GMT. This indicates the feasibility and robustness of both thermal

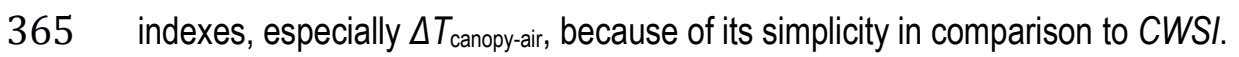

366 Additionally, thermal information obtained at 8:30 and 12:00 GTM in the lower and upper part was 367 related to the soil-water content measurements registered at different depths (Table 3). On overall, 368 thermal data obtained at 10:30 GTM did not reflect with enough robustness the soil-water status, in 369 comparison to the relationships obtained by using the thermal information derived from the 370 measurements taken at 12:00 GTM. In this agreement, as $T_{\mathrm{C}}$ as the related thermal indexes (CWSI and $\left.371 \Delta T_{\text {canopy-air }}\right)$ reported significant relationships with the $\theta$ obtained at different layers. Within the 
measurements taken at 12:00 GTM, the best relationships were obtained when comparing the thermal

373 information derived from the images taken in the lower part, and within them, by using the readings of $\theta$

374 corresponding to the first soil layers (at 10 and $20 \mathrm{~cm}$ depth, respectively). These results would suggest

375 the possibility of stablishing deficit irrigation programmes combining the information obtained in the

376 three levels of the soil-plant-atmosphere system: weather data ( $T_{\text {air }}$ and VPD), soil $(\theta)$ and plant ( $T_{\mathrm{C}}$ and

377 the related thermal indexes).

378 In agreement with this, the most significant relationships between these thermal indexes and 379 physiological parameters were obtained from readings taken at 12:00 GMT. Different functions were 380 defined depending of measurements being taken in the down part or in the upper part (Figure 8). One of 381 the most remarkable findings was the coincidence of the threshold values determined for $\Delta T_{\text {canopy-air }}$ and $382 \mathrm{CWSI}$ in terms of $\psi_{\mathrm{st}}, \mathrm{CWSI}$, and $A_{\mathrm{N}}$. As it can be observed in Figure 8, taking into account the readings 383 obtained in the upside, $\Delta T_{\text {canopy-air }}$ close to zero would be associated with $\psi_{\mathrm{st}} \leq-3 \mathrm{MPa} ; g_{\mathrm{s}} \leq 0.1 \mathrm{~mol} \mathrm{~m}^{-2}$ $384 \mathrm{~s}^{-1}$ and $A_{\mathrm{N}} \leq 8 \mu \mathrm{mol} \mathrm{m} \mathrm{m}^{-2} \mathrm{~s}^{-1}$, these values having been defined as indicators of situations of severe water stress (Fernández et al., 2013, Díaz-Espejo et al., 2012; Pérez-Martín et al., 2014; Hernández-Santana et al., 2016; Padilla-Díaz et al., 2016; among others). Something similar occurred taking as reference the values of $C W S I$, these being around 0.2 when $\Delta T_{\text {canopy-air }}$ was close to zero.

388 When considering the readings from the down part, the defined threshold values for a moderate-tosevere water stress for $\Delta T_{\text {canopy-air }}$ would be between 1.5 to $2{ }^{\circ} \mathrm{C}$, and between 0.4 to 0.5 in terms of CWSI (Figure 8).

391 Likewise, the applicability of these relationships is reduced at farm level, because of their high variability 392 within the orchard crop (García-Tejero et al., 2016), being more advisable the use of threshold values such as those derived from our results. In this regard, the robustness observed in the relationships between $\Delta T_{\text {canopy-air }}$ and the studied physiological parameters would justify the use of this thermal index stablishing a threshold value of $\Delta T_{\text {canopy-air }}$ close to zero when thermal readings are taken at 12:00 GTM in the down part of the canopy.

\section{Conclusions}

400 Crop water monitoring by using thermal information in olive is highly dependent on the procedure of 401 thermal acquisition. This work demonstrates the sensitiveness of this technique to the monitoring process; observing different results when measurements are taken at different hours and in different parts of the tree. Owing to this phenomenon, it could be difficult to compare our results with other obtained by using other kind of thermal sensors or also by applying different image processing and capture. In spite of this constraint, on overall, our result suggest that as $\Delta T_{\text {canopy-air }}$ as CWSI can be considered as robust indicators of crop-water status, as it was demonstrated by the relationships derived from monitored the physiological variables such as $g_{\mathrm{s}}$ or $\psi_{\text {st. }}$ In line with this conclusion, $\Delta T_{\text {canopy- }}$ air would allow stablishing deficit irrigations scheduling exclusively by using thermal information, not 
being necessary the use of relationships with other physiological parameters; and taking a threshold

410 value close to zero, as the point above which a moderate stress situation is being supported by the

411 crop. Likewise, as $\Delta T_{\text {canopy-air }}$ as CWSI showed significant relationships with crop water potential and gas

412 exchange measurements, especially with the readings taken at 12:30 GTM; being possible to estimate

413 these values throughout thermal information. Moreover, these thermal indexes showed significant

414 relationships with the soil water content at different depths, especially by using the soil moisture

415 readings taken in the first $20 \mathrm{~cm}$, evidencing the possibility of define irrigation programming based on

416 measurements of crop and soil water status. Nevertheless, these relationships could not be assumed

417 for other different situations, cultivars, image capturing and processing, being advisable to define

418 specific functions in the case of estimating the crop-water status or gas-exchange levels exclusively

419 using thermal information.

\section{Acknowledgements}

423 The author I. Garcia-Tejero has a contract co-financed by the Operational Programme of the European 424 Social Fund (ESF) 2007-2013 "Andalucia is moving with Europe". This work is funded by the MINECO 425 (Spanish Ministry of Economy and Competitiveness, research project AGL2012-34544; C.M. Padilla426 Díaz was supported by a predoctoral contract grant BES-2013-065380). Thanks to Antonio Montero for 427 his help during the field work. Thanks to the owners of Internacional Oli-varera, S.A.U. (Interoliva), for 428 allowing us to make the experiments in the Sanabria orchard.

\section{References}

Allen, R.G., Pereira, L.S., Raes, D., Smith, M. 1998 Crop evapotranspiration —guidelines for computing crop water requirements. FAO Irrigation and drainage paper 56. Food and Agriculture Organization, Rome.

Baluja, J., Diago, M.P., Balda, P., Zorer, R., Meggio, F., Morales, F., Tardaguila, J. 2012. Assessment of vineyard water status variability by termal and multispectral imagery using an unmanned aerial vehicle (UAV). Irrig. Sci. 30, 511-522.

Bellvert, J., Zarco-Tejada, P.J., Fereres, E., Girona, J. 2014. Mapping crop water stress index in a 'Pinot-noir' vineyard: comparing ground measurements with thermal remote sensing imagery from an unmanned aerial vehicle. Precision Agric. J. 15, 361-376.

444 Costa, J.M., Ortuño, M.F., Lopes, C.M., Chaves, M.M. 2012. Grapevine varieties exhibiting differences in stomatal response to water deficit. Funct. Plant Biol. 39, 179-189. 
Costa, J.M., Grant, O.M., Chaves, M.M. 2013. Thermography to explore plant-environment interactions. J. Exp. Bot. 64, 3937-3949.

Cohen, Y., Alchanatis, V., Meron, M., Saranga, Y. and Tsipris, J. 2005. Estimation of leaf water potential by thermal imagery and spatial analysis. J. Exp. Bot. 56:1843-1852.

Cohen, Y., Alchanatis, V., Sela, E., Saranga, Y., Cohen, S., Meron, M., Bosak, A., Tsipris, J., Ostrovsky, V., Orolov, V., Levi, A., Brikman, R. 2015. Crop water status estimation using thermography: multi-year mode I development using ground-based thermal images. Precision Agric. 16, 311329.

Cuevas, M.V., Torres-Ruiz, J.M., Alvarez, R., Jiménez, M.D., Cuerva, J., Fernández, J.E. 2010 Assessment of trunk diameter variation dderived indices as water stress indicators in mature olive trees. Agric Water Manage. 97, 1293-1302.

Cuevas, M.V., Martín-Palomo, M.J., Díaz-Espejo, A., Torres-Ruiz, J.M., Rodriguez-Dominguez, C.M., Perez-Martin, A., Pino-Mejías, R., Fernández, J.E. 2013. Assessing water stress in a hedgerow olive orchard from sap flow and trunk diameter measurements. Irrig Sci. 31, 729-746.

Diaz-Espejo, A., Buckley, T.N., Sperry, J.S., Cuevas, M.V., de Cires, A., Elsayed-Farag, S., MartinPalomo, M.J., Muriel, J.L., Perez-Martin, A., Rodriguez-Dominguez, C.M., Rubio-Casal, A.E., Torres-Ruiz, J.M., Fernández, J.E. 2012. Steps toward an improvement in process-based models of water use by fruit trees: a case study in olive. Agric. Water Manage. 114, 37-49.

Diaz-Espejo, A., Walcroft, A.S., Fernandez, J.E., Hafidi, B., Palomo, M.J., Giron, I.F. 2006. Modeling photosynthesis in olive leaves under drought conditions. Tree Physiology 26, 1445-1456.

Egea, G., Díaz-Espejo, A., Férnández, J.E. 2016. Soil moisture dynamics in a hedgerow olive orchard under well-watered and deficit irrigation regimes: Assessment, prediction and scenario analysis. Agric Water Manage. 164, 197-211.

Ennajeh, M., Tounekti, T., Vadel, A.M., Khemira, H., Cochard, H. 2008. Water relations and droughtinduced embolism in olive (Olea europaea) varieties 'Meski' and 'Chemlali' during severe drought. Tree Physiology 28, 971-976.

ESYRCE, 2014. Encuesta sobre superficies y Rendimientos. Spanish Ministry of Agriculture, Food and Environment. http://www.magrama.gob.es/es/estadistica/temas/estadisticasagrarias/agricultura/esyrce/

FAOSTAT, 2015. Food and Agriculture Division of United Nations. Statistic division. http://faostat3.fao.org/home/E

Fereres, E., Soriano, M.A. 2007. Deficit irrigation for reducing agricultural water use. J Exp Bot 58,147159.

Fernández, J.E. 2014a. Understanding olive adaptation to abiotic stresses as a tool to increase crop performance. Environ. Exp. Bot. 103, 158-179.

Fernández, J.E. 2014b. Plant-based sensing to monitor water stress: Applicability to commercial orchards. Agric. Water Manage. 142, 99-109. 
Fernández, J.E., Diaz-Espejo, A., d'Andria, R., Sebastiani, L., Tognetti, R. 2008b. Potential and limitations of improving olive orchard design and management through modelling. Plant Biosys. 142:130-137.

Fernández, J.E., Diaz-Espejo, A., Infante, J.M., Durán, P., Palomo, M.J., Chamorro, V., Girón, I.F., Villagarcía, L. 2006 Water relations and gas exchange in olive trees under regulated deficit irrigation and partial rootzone drying. Plant Soil 284:271-287.

Fernández, J.E., Green, S.R., Caspari, H.W., Diaz-Espejo, A., Cuevas, M.V. 2008a. The use of sap flow measurements for scheduling irrigation in olive, apple and Asian pear trees and in grapevines. Plant Soil 305:91-104.

Fernández, J.E., Moreno, F., Girón, I.F., Blázquez, O.M., 1997. Stomatal control of water use in olive tree leaves. Plant and Soil 190, 179-192.

Fernández, J.E., Rodriguez-Dominguez, C.M., Perez-Martin, A., Zimmermann, U., Rüger, S., MartínPalomo, M.J., Torres-Ruiz, J.M., Cuevas, M.V., Sann, C., Ehrenberger, W., Diaz-Espejo, A., 2011a. Online-monitoring of tree water stress in a hedgerow olive orchard using the leaf patch clamp pressure probe. Agric. Water Manage. 100, 25-35.

Fernández, J.E., Moreno, F., Martín-Palomo, M.J., Cuevas, M.V., Torres-Ruiz, J.M., Moriana, A., 2011b. Combining sap flow and trunk diameter measurements to assess water needs in mature olive orchards. Environ. Exp. Bot. 72, 330-338.

Fernández, J.E., Perez-Martin, A., Torres-Ruiz, J.M., Cuevas, M.V.,Rodriguez-Dominguez, C.M., Elsayed-Farag, S., Morales-Sillero, A., García, J.M., Hernandez-Santana, V., Diaz-Espejo, A., 2013. A regulated deficit irrigation strategy for hedgerow olive orchards with high plant density. Plant Soil 372, 279-295.

García-Tejero, I., Durán-Zuazo, V.H., Muriel-Fernández, J.L., Jiménez-Bocanegra, J.A. 2011. Linking canopy temperature and trunk diameter fluctuations with other physiological water status tools for irrigation scheduling in citrus orchards. Functional Plant Biology 38, 1-12.

García-Tejero, I., Durán-Zuazo, V.H., Arriaga, J., Hernández, A., Vélez, L.M., Muriel-Fernández, J.L. 2012. Approach to assess infrared thermal imaging of almond trees under water-stress conditions. Fruits, 67, 463-474.

García-Tejero, I.F., Muriel-Fernández, J.L., Durán-Zuazo, V.H., Arriaga, J. 2013. Uso eficiente del agua en la agricultura. IFAPA-CAPDR. 94 pp.

García-Tejero, I.F., Costa, J.M., Egipto, R., Lima, R.S.N., Durán, V.H., Lópes, C., Chaves, M.M. 2016. Thermal data to monitor crop-water status in irrigated Mediterranean viticulture. Agric. Water Manage. 2016. (Accepted)

Geerts, S., Raes, D. 2009. Deficit irrigation as an on farm strategy to maximize crop water productivity in dry areas. Agric Water Manag. 96, 1275-1284

Gómez-del-Campo, M., 2013. Summer deficit-irrigation strategies in a hedgerow olive orchard cv. 'Arbequina': effect on fruit characteristics and yield. Irrig. Sci. 31, 259-269. 
González-Dugo, V., Zarco-Tejada, P.J., Berni, J.A.J., Suarez, L., Goldhamer, D.A., Fereres, E. 2012. Almond tree canopy temperature reveals intra-crown variability that is water stress-dependent. Agric. For. Meteorol. 154-155, 156-165.

Gonzalez-Dugo, V., Zarco-Tejada, P., Fereres, E. 2014. Applicability and limitations of using the crop water stress index as an indicator of water deficits in citrus orchards. Agric. For. Meteorol. 198199, 94-104.

Grant, O.M., Chaves, M.M., Jones, H.G., 2006. Optimizing thermal imaging as a technique for detecting stomatal closure induced by drought stress under greenhouse conditions Physiol. Plant. 127, 507-518.

Idso, S.B., Jackson, R.D., Pinter, P.J.J., Reginato, R.J., Hatfield, J.L. 1981. Normalizing the stress degree-day parameter for environmental variability. Agric. Meteorol. 24, 45-55.

Iniesta, F., Testi, L., Orgaz, F., Villalobos, F.J. (2009). The effects of regulated and continuous deficit irrigation on the water use, growth and yield of olive trees. Eur. J. Agron. 30, 258-265.

IPCC, 2014. Cambio climático 2014. Impactos, adaptación y vulnerabilidad. 40 pp. Available at: https://www.ipcc.ch/pdf/assessment-report/ar5/wg2/ar5_wgll_spm_es.pdf.

Jackson, R.D., Idso, S.B., Reginato, R.J., Pinter, P.J. 1981. Canopy temperature as a crop water-stress indicator. Water Resources Res. 17, 1133-1138. Jackson, R. 1982. Canopy temperature and crop water stress. Adv. Irrig. 1, 43-85. Jones, H.G. 1999. Use of infrared thermometry for estimation of stomatal conductance as a possible aid to irrigation scheduling. Agric. Forest Meteorol. 95, 139-149.

Jones, H.G., Stoll, M., Santos, T., de Sousa, C., Chaves, M.M., Grant, O.M. 2002. Use of infra-red thermography for monitoring stomatal closure in the field: application to the grapevine. J. Exp. Bot. 53, 2249-2260.

Jones, H.G. 2004. Irrigation scheduling: advantages and piffalls of plant-based methods. J. Exp. Bot. $55,2427-2436$.

Jones H.G., Serraj, R., Loveys, B.R., Xiong, L., Wheaton, A., Price, A.H. 2009. Thermal infrared

552 Martín-Vertedor, A.I., Pérez Rodríguez, J.M., Losada, H.P., Castiel, E.F. 2011. Interactive responses to 553 water deficits and crop load in olive (Olea europea L., cv. Morisca). Growth and water relations. Agric. Water Manage. 98, 941-949. 
Medrano, H., Escalona, J.M., Bota, J., Gulías, J., Flexas, J. 2002. Regulation of photosynthesis of C3 plants in response to progressive drought: stomatal conductance as a reference parameter. Ann. Bot. 89, 895-905

Möller, M., Alchanatis, V., Cohen, Y., Meron, M., Tsipris, J., Naor, A., Ostrovsky, V., ,Sprintsin, M., Cohen, S. 2007. Use of thermal and visible imagery for estimating crop water status of irrigated grapevine. J. Exp. Bot. 58, 827-838. DOI: 10.1093/jxb/erl115.

Moriana, A., Girón, I.F., Martín-Palomo, M.J., Conejero, W., Ortuño, M.F., Torrecillas, A., Moreno, F. 2010. New approach for olive trees irrigation scheduling using trunk diameter sensors. Agric. Water Manage. 97, 1822-1828.

Moriana, A., Pérez-López, D., Prieto, M.H., Ramírez-Santa-Pau, M., Pérez-Rodríguez, J.M., 2012. Midday stem water potential as a useful tool for estimating irriagtion requirements in olive trees. Agricultural Water Management 112, 43-54.

Osroosh, Y., Peters, R.T., Campbell, C.S. 2016. Daylight crop water stress index for continuous monitoring of water status in apple trees. Irrig. Sci, 34, 209-219.

Padilla-Díaz, C.M., Rodriguez-Dominguez, C.M., Hernandez-Santana, V., Perez-Martin A., Fernández, J.E. 2016. Scheduling regulated deficit irrigation in a hedgerow olive orchard from leaf turgor pressure related measurements. Agric. Water Manage. 164, 28-37.

Perez-Martin, A., Michelazzo, C., Torres-Ruiz, J.M., Flexas, J., Fernández, J.E., Sebastiani, L., DiazEspejo, A. 2014. Regulation of photosynthesis and stomatal and mesophyll conductance under water stress and recovery in olive trees: correlation with gene expression of carbonic anhydrase and aquaporins. J. Exp. Bot. 65, 3143-3156.

Poblete-Echeverria, C., Ortega-Farías, S., Zúñiga, M. 2014. Use of infrared thermography on canopies as indicator of water stress in Arbequina olive orchards. Acta Hort, 1057, 399-404.

Poblete-Echeverría, C., Sepúlveda-Reyes, D., Ortega-Farias, S., Zúñiga, M., Fuentes, S. 2016. PLant wáter stress detection based on aerial and terrestrial infrered thermography: a study case from vineyard and olive orchard. Acta Hort 1112, 141-146

Pou, A., Diago, M.P., Medrano, H., Baluja, J., Tardaguila, J. 2014. Validation of thermal indices for water stress status identification in grapevine. Agric. Water Manage. 134, 60-72.

Rius X, Lacarte JM (015 La revolución del olivar. El cultivo en seto, $2^{\text {nd }}$ Ed. Barcelona

Ruiz-Sanchez, M.C., Domingo, R., Castel, J.R. 2010 Review. Deficit irrigation in fruit trees and vines in Spain. Span J Agric Res 8, S5-S20.

Sepulcre-Cantó, G., Zarco-Tejada, P.J., Jiménez-Muñoz, J.C., Sobrino, J.A., de Miguel, E., Villalobos, F.J. 2006. Detection of water stress in an olive orchard with thermal remote sensing imagery. Agric. For. Meteorol. 136, 31-44.

Testi, L., Goldhamer, D.A., Iniesta, F., Salinas, M. 2008. Crop water stress index is a sensitive water stress indicator in pistachio trees. Irrig. Sci. 26,395-405. 
591 Torres-Ruiz, J.M., Diaz-Espejo, A., Morales-Sillero, A., Martín-Palomo, M.J., Mayr, S., Beikircher, B., 592 Fernández, J.E. 2013a. Shoot hydraulic characteristics, plant water status and stomatal 593 response in olive trees under different soil water conditions. Plant and Soil 373, 77-87.

594 USDA 2010 Keys to soil taxonomy (11th Edition). United States Department of Agriculture, Natural 595 Resource Conservation Service, $334 \mathrm{pp}$.

596 Zimmerman, D., Reuss, R., Westhoff, M., Geßner, P., Bauer, W., Bamberg, E., Bentrup, F.W., 597 Zimmermann, U. 2008. A novel, non-invasive, online-monitoring, versatile and easy plant-based $598 \quad$ probe for measuring leaf water status. J. Exp. Bot. 59, 3157-3167

599

600

601

602

603

604

605

606

607

608

609

610

611

612

613

614

615

616

617

618

619

620

621

622

623

624

625

626

627 
629 Table 1. Fitted parameters for the baselines from non-stressed trees $\left(\Delta T_{\text {canopy-air }}=a+b^{*} V P D\right)$.

630 Data obtained for the DOY 169 to $253(n=8)$.

631

\begin{tabular}{lllll}
\hline GTM & Side & Slope $\left({ }^{\circ} \mathbf{C ~ k P a - 1}\right)$ & Intercept $\left({ }^{\circ} \mathbf{C}\right)$ & $\mathbf{R}^{2}$ \\
\hline \multirow{2}{*}{$\mathbf{0 8 : 3 0}$} & Down & -1.92 & 5.65 & 0.76 \\
& Upper & -1.74 & 2.08 & 0.87 \\
\multirow{2}{*}{ 12:00 } & Down & -0.39 & 0.95 & 0.82 \\
& Upper & -0.67 & 0.09 & 0.87 \\
\hline
\end{tabular}

Table 2. Pearson's correlation coefficients between thermal indicators and physiological

633 variables at the two sampling times and sampled canopy location.

\begin{tabular}{|c|c|c|c|c|c|c|}
\hline GMT & location & Thermal Indicator & $\psi_{\text {st }}$ & $A_{N}$ & $g_{\mathrm{s}}$ & $E$ \\
\hline \multirow{6}{*}{$10: 30$} & \multirow{3}{*}{ Down } & $T_{\mathrm{C}}$ & $-0.61^{* *}$ & $-0.74^{* *}$ & $-0.74^{\star *}$ & $-0.53^{* *}$ \\
\hline & & $\Delta T_{\text {canopy-air }}$ & $-0.42^{*}$ & ns & $-0.41^{*}$ & $-0.55^{\star *}$ \\
\hline & & CWSI & $-0.66^{* *}$ & $-0.61^{* *}$ & $-0.69^{* *}$ & $-0.71^{* *}$ \\
\hline & \multirow{3}{*}{ Up } & $T_{\mathrm{C}}$ & ns & $-0.50^{*}$ & $-0.53^{* *}$ & ns \\
\hline & & $\Delta T_{\text {canopy-air }}$ & ns & ns & ns & ns \\
\hline & & CWSI & ns & ns & ns & ns \\
\hline \multirow{6}{*}{$12: 30$} & \multirow{3}{*}{ Down } & $T_{\mathrm{C}}$ & $-0.57^{\star *}$ & $-0.68^{* \star}$ & $-0.65^{\star \star}$ & $-0.46^{*}$ \\
\hline & & $\Delta T_{\text {canopy-air }}$ & $-0.78^{\star *}$ & $-0.81^{* *}$ & $-0.80^{* *}$ & $-0.78^{* *}$ \\
\hline & & CWSI & $-0.74^{* *}$ & $-0.83^{* *}$ & $-0.80^{* *}$ & $-0.70^{* *}$ \\
\hline & \multirow{3}{*}{ Up } & $T_{\mathrm{C}}$ & $-0.57^{* *}$ & $-0.70^{* \star}$ & $-0.65^{\star *}$ & $-0.48^{*}$ \\
\hline & & $\Delta T_{\text {canopy-air }}$ & $-0.83^{* *}$ & $-0.83^{* *}$ & $-0.78^{* *}$ & $-0.81^{* *}$ \\
\hline & & CWSI & $-0.71^{* *}$ & $-0.80^{\star *}$ & $-0.77^{* *}$ & $-0.70^{* *}$ \\
\hline
\end{tabular}

$634 \psi_{\text {st, }}$ stem-water potential;; $A_{N}$, net-photosynthesis; $g_{\mathrm{s}}$, stomatal conductance to water vapour; $E$,

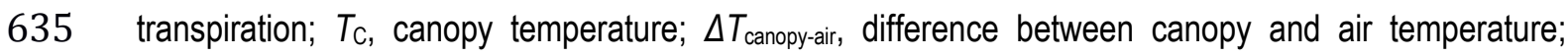

$636 \mathrm{CWSI}$, crop-water stress index. ns, no significant relationships; * and ${ }^{* *}$ evidence significant correlations

637 at 95 and $99 \%$, respectively.

638

639

640

641

642

643

644

645

646

647 
Table 3. Pearson's correlation coefficients between thermal indicators obtained at the two

649 sampling times and sampled canopy location; and the volumetric soil-water content $\left(\theta, \mathrm{m}^{3} \mathrm{~m}^{-3}\right)$

650 measured at different depths $(10,20,30$ and $40 \mathrm{~cm}$, respectively).

\begin{tabular}{|c|c|c|c|c|c|c|}
\hline GMT & location & Thermal Indicator & $\theta_{10}$ & $\theta_{20}$ & $\theta_{30}$ & $\theta_{40}$ \\
\hline \multirow{6}{*}{ 10:30 } & \multirow{3}{*}{ Down } & $T_{\mathrm{C}}$ & $-0.58^{\star \star}$ & $-0.66^{* *}$ & $-0.52^{*}$ & $-0.48^{*}$ \\
\hline & & $\Delta T_{\text {canopy-air }}$ & ns & ns & ns & ns \\
\hline & & CWSI & $-0.44^{*}$ & $-0.57^{*}$ & $-0.54^{*}$ & $-0.46^{*}$ \\
\hline & \multirow{3}{*}{ Up } & $T_{\mathrm{C}}$ & $-0.43^{*}$ & $-0.49^{*}$ & ns & ns \\
\hline & & $\Delta T_{\text {canopy-air }}$ & ns & ns & ns & ns \\
\hline & & CWSI & ns & ns & ns & ns \\
\hline \multirow{6}{*}{$12: 30$} & \multirow{3}{*}{ Down } & $T_{\mathrm{C}}$ & $-0.76^{\star \star}$ & $-0.57^{\star \star}$ & $-0.42^{*}$ & $-0.39^{*}$ \\
\hline & & $\Delta T_{\text {canopy-air }}$ & $-0.82^{\star *}$ & $-0.76^{* \star}$ & $-0.65^{\star \star}$ & $-0.59^{* *}$ \\
\hline & & CWSI & $-0.79^{* *}$ & $-0.72^{\star *}$ & $-0.60^{\star *}$ & $-0.56^{*}$ \\
\hline & \multirow{3}{*}{ Up } & $T_{\mathrm{C}}$ & $-0.58^{\star *}$ & $-0.69^{* *}$ & $-0.46^{*}$ & $-0.48^{*}$ \\
\hline & & $\Delta T_{\text {canopy-air }}$ & $-0.58^{* *}$ & $-0.60^{* *}$ & $-0.55^{\star}$ & $-0.61^{* *}$ \\
\hline & & CWSI & $-0.69^{* *}$ & $-0.70^{* *}$ & $-0.62^{* *}$ & $-0.66^{* *}$ \\
\hline
\end{tabular}

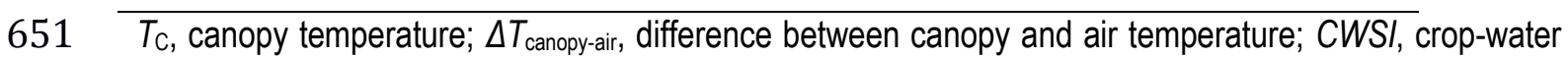

652 stress index; $\theta_{10}, \theta_{20}, \theta_{30}, \theta_{40}$, volumetric soil-water content at 10, 20, 30 and $40 \mathrm{~cm}$ depth respectively;

653 ns, no significant relationships; ${ }^{*}$ and ${ }^{* *}$ evidence significant correlations at 95 and $99 \%$, respectively.

654

655

656

657

658

659

660

661

662

663

664

665

666

667

668

669

670 
673

674

675

676

677

678

679

680

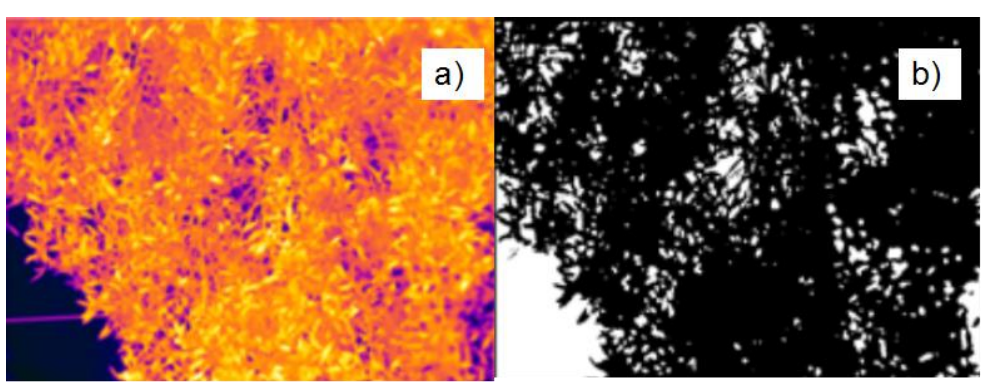

Figure 1. False colored image of downside olive tree (a) and post-processing image (monochrome image) representing in black the areas corresponding to pixels of leaves (b). This process allows deleting those pixels corresponding to branches, stem and the background (all these areas in white).

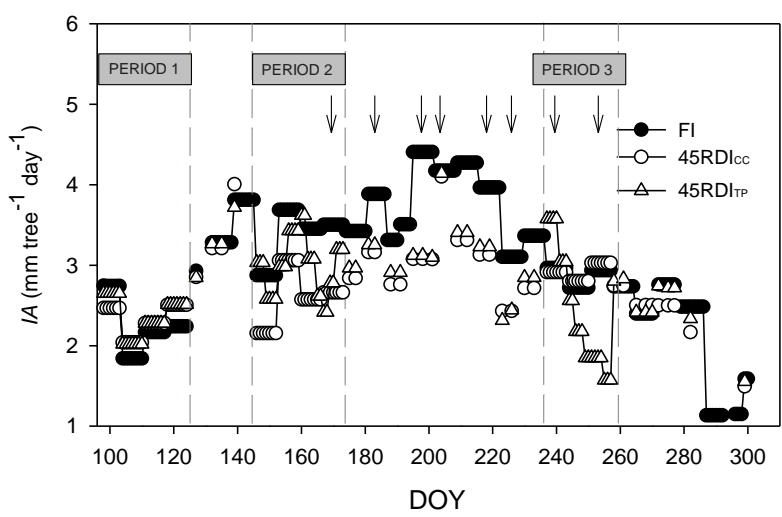

Figure 2. Irrigation applied (IA) in each irrigation treatment: full-irrigated (FI), crop-coefficient regulated deficit irrigation (45RDIcc), regulated deficit irrigation based on turgor pressure related measurements (45RDITP). Arrows down show the days on which the thermal measurements were made..

681
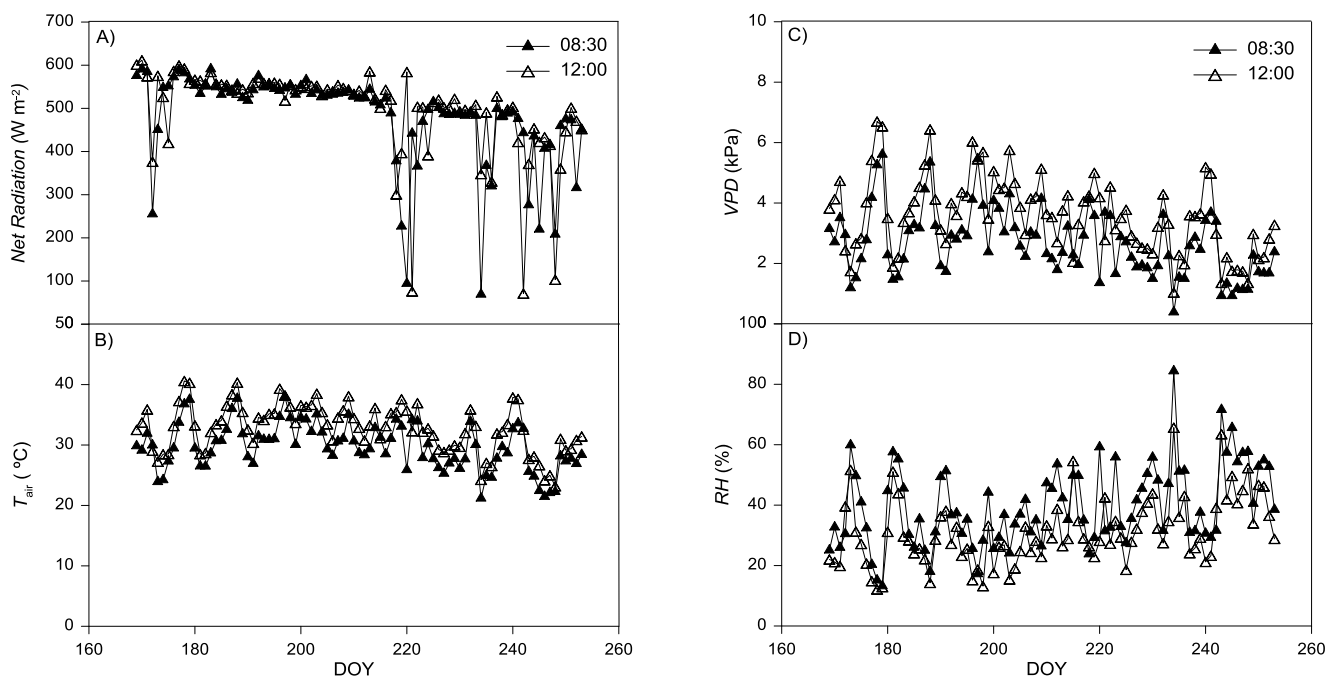

Figure 3. Seasonal course of net radiation (A), air temperature (B), vapour pressure deficit $(C)$ and relative humidity (D), measured at 08:30 and 12:00 GMT. 

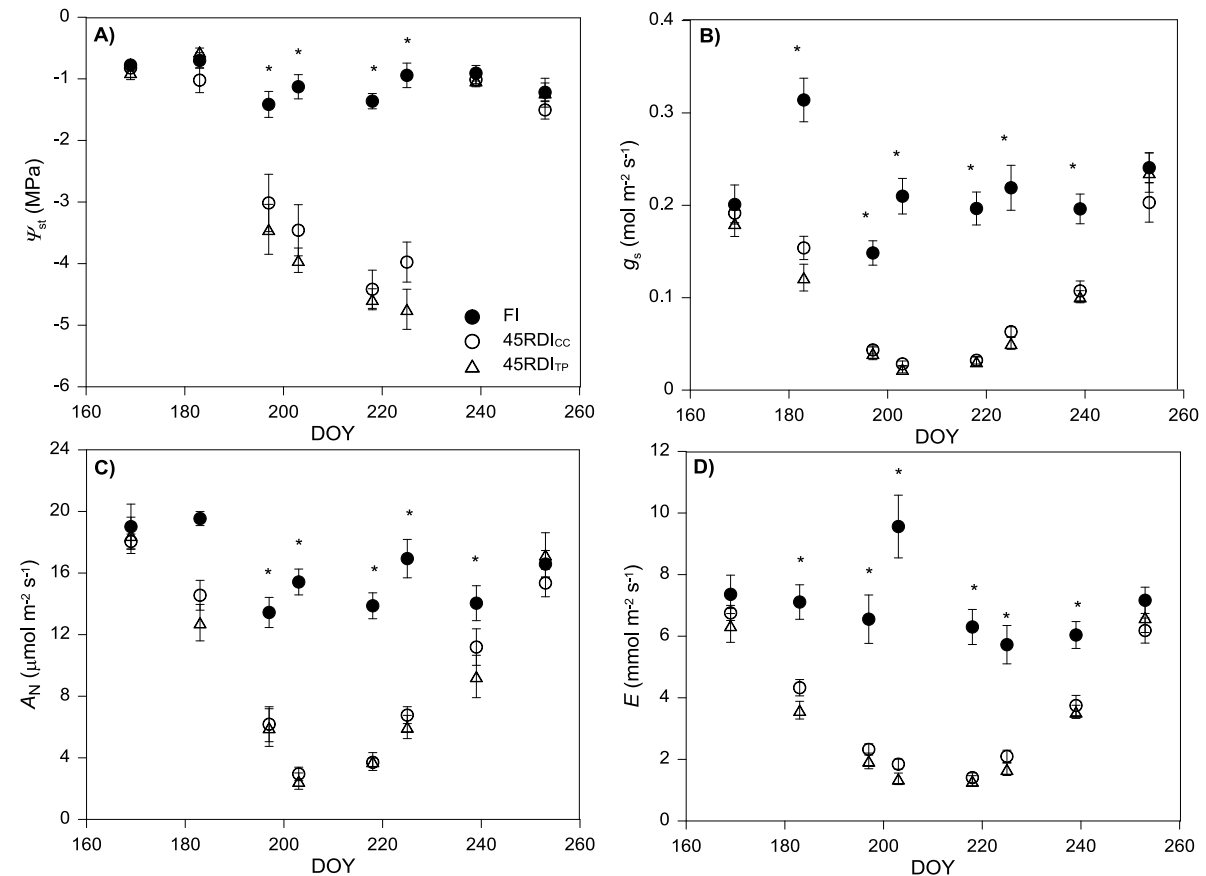

Figure 4. Seasonal course of stem water potential $\left(\psi_{\mathrm{st}}\right)(\mathrm{a})$, stomatal conductance $\left(g_{\mathrm{s}}\right)(\mathrm{b})$, net $\mathrm{CO}_{2}$ assimilation $\left(A_{N}\right)(c)$, and transpiration $(E)(d)$, measured in trees of the three irrigation treatments. * shows significant differences between $\mathrm{FI}$ and RDI trees $(p<0.05)$. Each point corresponds to the average value
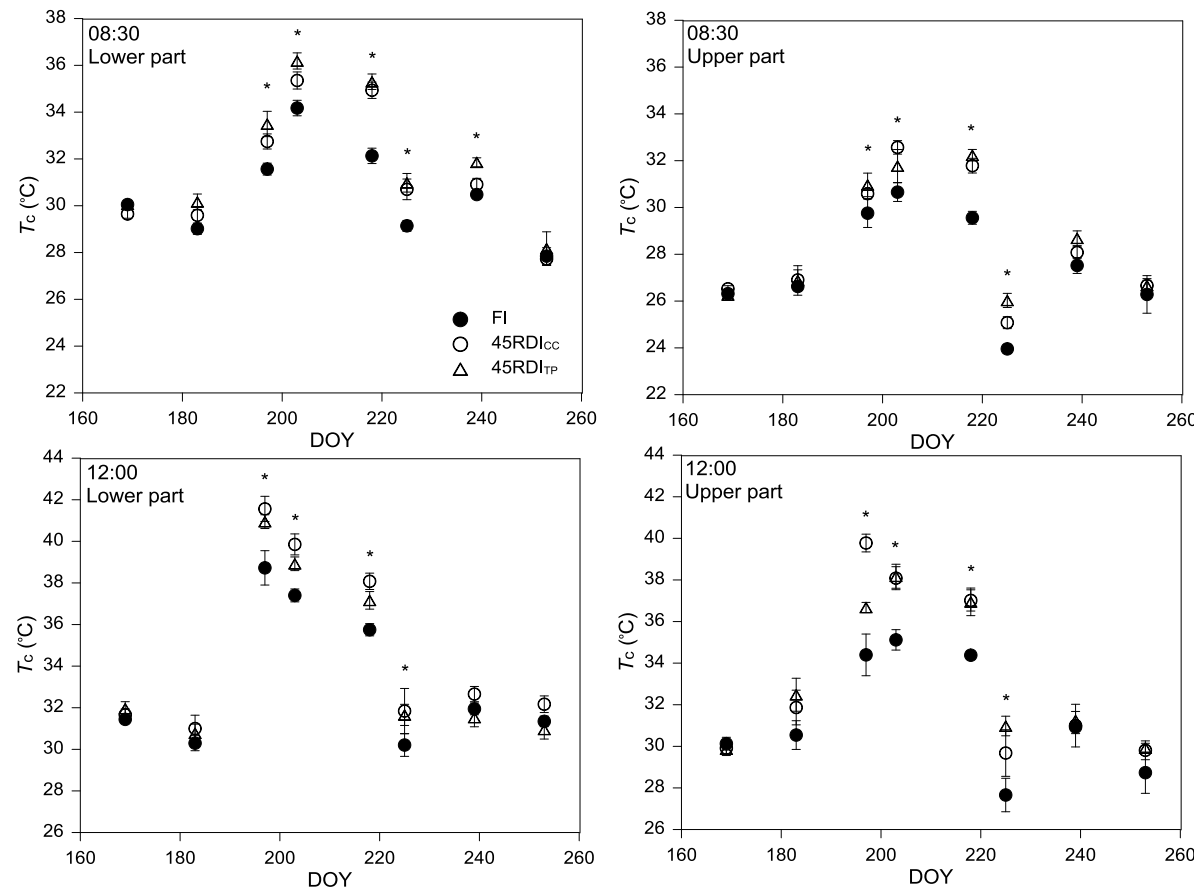

693 Figure 5. Seasonal evolution of the canopy temperature $\left(T_{c}\right)$ measured at the two times (08:30 694 and 12:00 GTM) and sampling locations in the canopy (lower and upper part), in trees of the 695 three irrigation treatments. * shows significant differences between FI and RDI treatments $(p<0.05)$. 696 Each point corresponds to the average value for each treatment $(n=8)$. Vertical bars represent the standard error of the mean. 

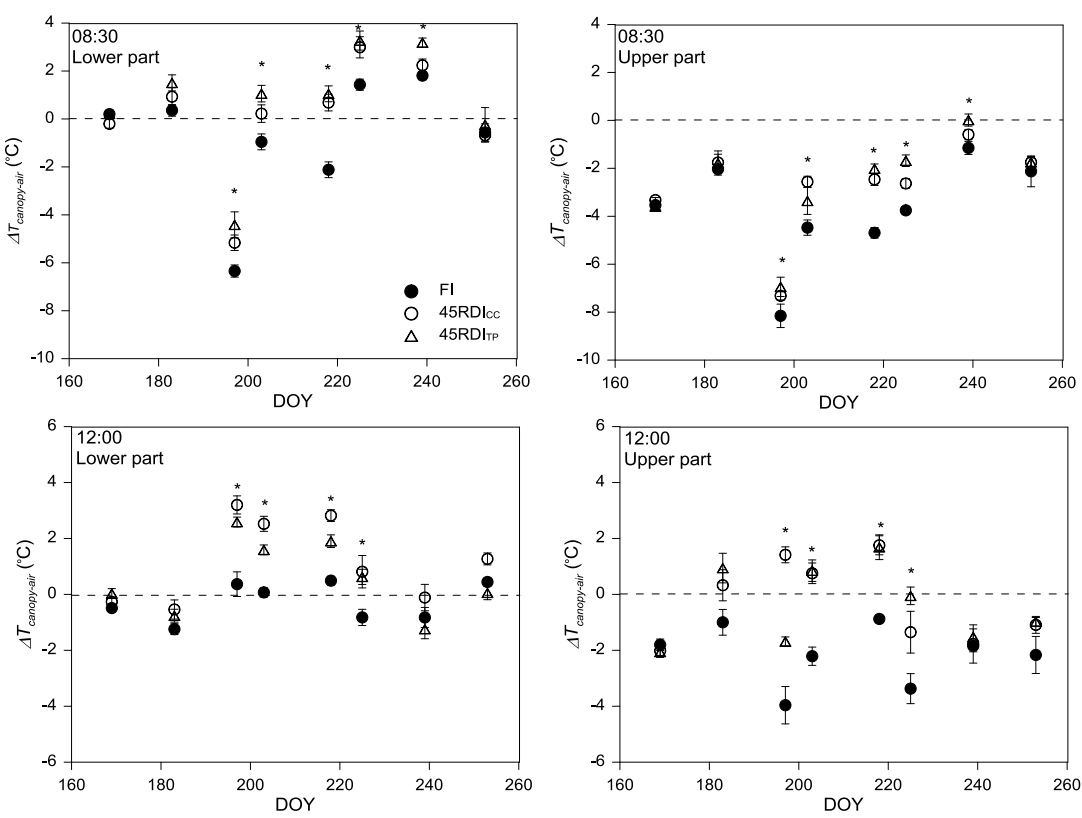

699

Figure 6. Seasonal evolution of the difference between canopy and air temperature ( $\Delta T_{\text {canopy-air }}$ ) measured at the two times (08:30 and 12:00 GTM) and sampling locations in the canopy (lower and upper part), in trees of the three irrigation treatments. * shows significant differences between $\mathrm{FI}$ and RDI treatments $(\mathrm{p}<0.05)$. Each point corresponds to the average value for each treatment $(n=8)$. Vertical bars represent the standard error of the mean.

705
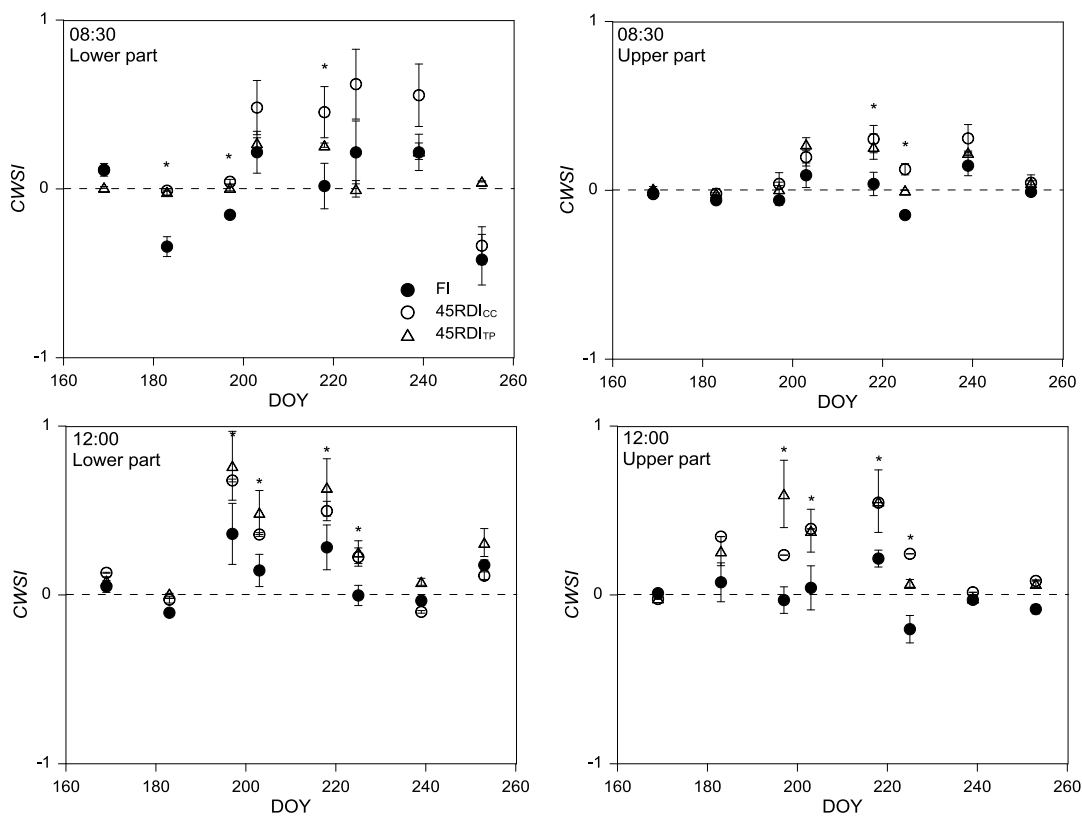

Figure 7. Seasonal evolution of the Crop Water Stress Index (CWSI) measured at the two times (08:30 and 12:00 GTM) and sampling locations in the canopy (lower and upper part), in trees of the three irrigation treatments. * shows significant differences between FI and RDI treatments $(p<0.05)$. Each point corresponds to the average value for each treatment $(n=8)$. Vertical bars

711 represent the standard error of the mean. 

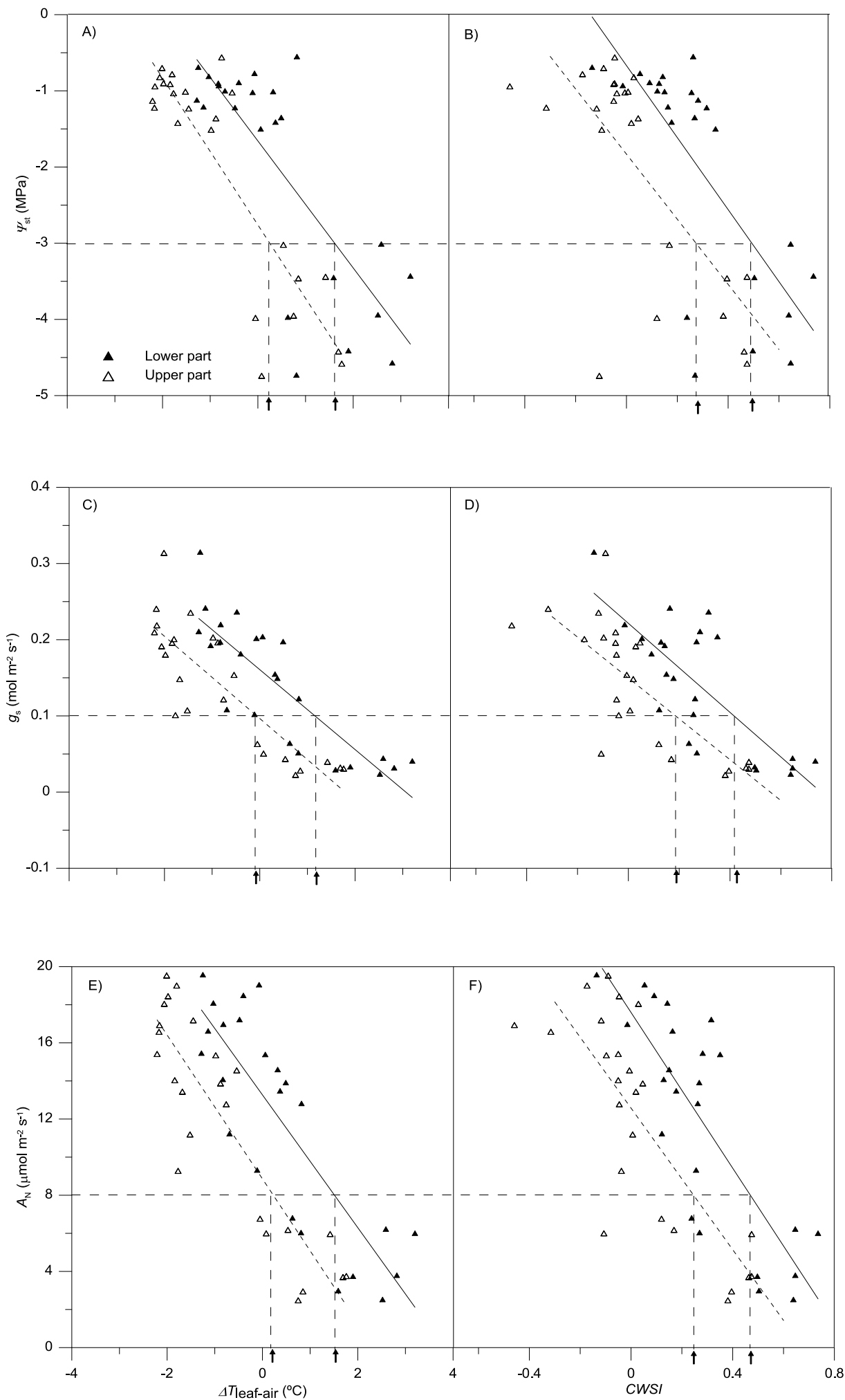

714 Figure 8. Linear regressions between the difference between canopy and air temperature

$715\left(\Delta T_{\text {canopy-air }}\right)$ and the crop-water stress index (CWSI, dimensionless) with the stem-water potential

$716\left(\Psi_{\mathrm{st}}\right)$, stomatal conductance $\left(g_{\mathrm{s}}\right)$ and net $\mathrm{CO}_{2}$ assimilation $\left(A_{n}\right)$, using the readings taken at 12:00

717 in the lower part of the canopy $(\mathbf{\Lambda})$ and in the upper part $(\Delta)$. 